\title{
Evidence-based support for autistic people across the lifespan: Maximizing potential, minimizing barriers, and optimizing the person-environment fit
}

\author{
Meng-Chuan Lai 1,2,3,*, Evdokia Anagnostou ${ }^{4,5}$, Max Wiznitzer ${ }^{6}$, Carrie Allison ${ }^{2}$, and \\ Simon Baron-Cohen ${ }^{2,7}$
}

1 Centre for Addiction and Mental Health and The Hospital for Sick Children, Department of Psychiatry, University of Toronto, Toronto, Ontario, Canada

2 Autism Research Centre, Department of Psychiatry, University of Cambridge, Cambridge, United Kingdom

3 Department of Psychiatry, National Taiwan University Hospital and College of Medicine, Taipei, Taiwan

${ }^{4}$ Bloorview Research Institute, Holland Bloorview Kids Rehabilitation Hospital, Toronto, Ontario, Canada

${ }^{5}$ Department of Paediatrics, University of Toronto, Toronto, Ontario, Canada

${ }^{6}$ Division of Pediatric Neurology, Rainbow Babies and Children's Hospital, Cleveland, Ohio, USA

7 Cambridgeshire and Peterborough National Health Service Foundation Trust, Cambridge, United Kingdom

* Correspondence to: Dr Meng-Chuan Lai, Child, Youth and Emerging Adult Program, Centre for Addiction and Mental Health, 80 Workman Way, Toronto, ON M6J 1H4, Canada. Email: mengchuan.lai@utoronto.ca 


\begin{abstract}
Autism is both a medical condition that can give rise to disability and an example of human neurological variation ('neurodiversity') that contributes to identity, with cognitive assets and challenges. We refer to this as the dual nature of autism. Enhancing adaptation and wellbeing is the ultimate goal for intervention/support. Evidence-based support for autistic people across the lifespan is emerging. Support should be collaborative between autistic individuals, their families, and service providers, taking a shared decision-making approach. To maximize the individual's potential, comprehensive early intervention and parent-mediated intervention, ideally taking a naturalistic approach, may help support the early development of adaptive, cognitive and language skills. Targeted intervention of social skills and aspects of cognition may help but challenges remain for behavioural flexibility and generalisation to different contexts. To minimize barriers for an individual's development and adaptation, augmentative and alternative communication may potentially reduce communication difficulties. Alleviating co-occurring health challenges by timely medical, pharmacological or psychological interventions is essential. Finally, optimizing the person-environment fit by creating autism-friendly contexts through reasonable adjustments is critical. This involves supporting families, reducing stigma, enhancing peer understanding of autism, and promoting true inclusion in education, community and work environments, alongside strong advocacy.
\end{abstract}

Key words: autism, support, intervention, treatment, adaptation, development, lifespan, health, disability, neurodiversity 


\section{The duality of autism}

Autism spectrum disorder/conditions (ASD or ASC (Lai and Baron-Cohen, 2015), henceforth 'autism') are atypical neurodevelopmental conditions that emerge early in life (Varcin and Jeste, 2017), with strong genetic aetiologies (Tick et al., 2016) shaped by subsequent gene-environmental interplays (Mandy and Lai, 2016). Autism has lifespan impact on an individual's development and adaptation (Howlin and Magiati, 2017). As a result of evolving diagnostic concepts, recognition of the spectrum and its multi-subgroup nature (Lai et al., 2013), along with increased awareness (Liu et al., 2010), autism formerly regarded as rare - is now considered relatively common. Globally, close to $1 \%$ of the population has a formal autism diagnosis (Baxter et al., 2015). In developed countries the prevalence is close to $1 \cdot 5 \%$ (Lyall et al., 2017), with a male:female ratio of 3-4:1 (Loomes et al., 2017).

Characteristics associated with autism (ie, 'autistic traits') fall along a spectrum in the general population across dimensions of social-communication, repetitive and stereotyped behaviours, and other non-clinical and cognitive features (Constantino et al., 2010, Ruzich et al., 2015, Skuse et al., 2009). Elevated autistic traits are particularly common in family members of people who have an autism diagnosis (Pickles et al., 2000, Piven et al., 1997, Wheelwright et al., 2010). Both clinical autism and the dimensional traits are associated with the additive effect of common and rare genetic variations (Geschwind and State, 2015, Robinson et al., 2016, Weiner et al., 2017), although their exact causal roles remain unclear.

The dimensional nature of autistic traits makes it challenging to draw a clear diagnostic line, especially when genetic or other diagnostic biomarkers are not yet available (Constantino and Charman, 2016). From a medical perspective, a clinical diagnosis is made based on both the intensity of autistic characteristics and clinically significant impairment of adaptive functioning that is largely attributable to autism characteristics (American Psychiatric Association, 2013). From a developmental perspective (Sameroff and Mackenzie, 2003), adaptation is the product of the transaction between an individual and their environmental contexts, rather than an individual's autism characteristics per se. Therefore, an individual with high autistic traits may not 
necessarily require a clinical diagnosis, unless a poor person-environment fit results in impaired adaptive functioning (Lai and Baron-Cohen, 2015, Mandy and Lai, 2016).

These two perspectives lead us to the concept of the duality of autism. On one hand, autism is a medical condition entailing disability - the diagnosis can not be made if there is no evidence of disability or significant impairment in everyday functioning - resulting from atypical developmental neurobiology and requiring treatment/intervention to alleviate the disability. On the other hand, autism is one form of human variation (the 'neurodiversity' view) along specific dimensions and includes strengths, differences, and challenges. Acknowledging the duality of autism, with a both-and rather than an either-or perspective, is central when supporting autistic people. This both-and perspective may help reduce the tension between the 'neurodiversity' and 'medical' views when it comes to intervention/support (Panel 1). Indeed, we argue that polarising these two views as if they are mutually exclusive will hold back progress both scientifically and clinically, and lead to unnecessary conflict between different stakeholder groups. Alleviating distress and improving adaptive functioning and quality of life are the targets of medical, psychological, social and environmental interventions/treatments for autism (Constantino and Charman, 2016), including those related to co-occurring developmental disabilities (eg, language and communication difficulties), medical conditions (eg, epilepsy) and mental health challenges (eg, ADHD, anxiety, irritability, depression) that often result in increased suffering (Helles et al., 2017). The duality of autism view accommodates 'autism as a difference' and respects the individual and their diversity, whilst still acknowledging that there are improvements we as individuals and as a society can make to the person-environment fit and creating autism-friendly environments.

\section{A lifespan perspective}

Autism should be identified early in life, but for some it may not be recognized until adolescent or adult years, due to variation in the developmental courses, the presence of co-occurring psychiatric disorders, limited information of early childhood characteristics that can be influenced by changes in societal definition of normative behaviours, and learned coping strategies that can mask social differences (Lai and Baron-Cohen, 2015). 
Understanding the core characteristics of autism and associated challenges over the lifespan is necessary for adequate assessment and support (Lai and Baron-Cohen, 2015, Pilling et al., 2012).

Autistic children $^{1}$ who are diagnosed early in life mostly continue to meet criteria in adulthood, with large variation of outcomes. There is contradictory evidence regarding the proportion of autistic children achieving 'good' outcomes as adults, and lack of agreement over how this should be defined/measured or how outcome can be improved (Howlin and Magiati, 2017). The general trends are: (1) cognitive abilities tend to remain stable over time; (2) communication and social skills improve over time, more so in those without intellectual disabilities; (3) restricted interests and repetitive behaviours often remain stable or lessen (although their manifestation changes with age), but in those with intellectual disabilities these may increase; (4) regarding academic or employment outcomes, the majority of autistic people perform at a lower level than predicted by their IQ; (5) many autistic adults report negative job experiences related to their work social environment; (6) independent living is only achieved in 4-20\% of autistic adults, with the majority in residential housing or living with family members (Happe and Charlton, 2012, Perkins and Berkman, 2012, Ratto and Mesibov, 2015). Childhood factors predicting adulthood outcome include intellectual and verbal functioning, intensity of early autistic features, perceived stress, co-occurring psychiatric and medical challenges, inclusion in social and academic activities in school, and availability of good quality educational and vocational programming (Howlin and Magiati, 2017, Howlin and Moss, 2012).

There is a growing understanding of autistic individuals' needs during college life. They have potential difficulties with socialization and pragmatic skills, skills related to independent living, executive functioning, inferential and critical thinking, with bullying,

\footnotetext{
${ }^{1}$ We acknowledge that there is no single, consensual way to refer to autistic people. From a recent survey of a UK autism stakeholder community (Kenny, L., Hattersley, C., Molins, B., Buckley, C., Povey, C. \& Pellicano, E. (2016). Which terms should be used to describe autism? Perspectives from the UK autism community. Autism 20, 442-62.), preferences vary between person-first language ('individual with autism') which is more endorsed by health-care professionals and identity-first language ('autistic individual') which is more endorsed by autistic adults, family members and friends. In this paper we primarily use identity-first language as autistic people's views should be respected and take priority over how they are discussed. Person-first language is also used in various occasions to reflect the status quo and to respect the preferences of different parties.
} 
and the consequences of their social naïveté. Colleges have responded by providing support services for their needs (Gelbar et al., 2014, van Schalkwyk and Volkmar, 2017). Many autistic individuals are interested in and engage in sexual and romantic relationships, and there is a greater diversity in sexual orientation and gender identity compared to the general population (Dewinter et al., 2017). There are concerns however, whilst autistic people have access to sex education, programs do not consistently address their specific needs and learning styles (Turner et al., 2017).

While there are concerns about involvement in the criminal justice system, the data are contradictory. Review of legal decisions shows that autistic individuals in the legal system tend to commit offences related to arson, computer-misuse, stalking, sexual crimes, violence and neglect, and dishonesty; yet it is more likely that autistic individuals are the victims rather than the defendants in the criminal justice system (Freckelton, 2013, Ratto and Mesibov, 2015).

\section{Current evidence-base, stakeholder perspectives and shared decision-making}

Support for autistic individuals and their families are inherently complex, partly due to the large individual differences within the autism spectrum. The literature of intervention/treatment or support is diverse, spanning comprehensive intervention in early years to targeted skill building later in life, from behavioural-educational to pharmacological approaches, and from targeting core autism characteristics to focusing on co-existing health challenges (Lai et al., 2014, Wong et al., 2015). What is concerning is that many interventions in use actually have little evidence (Green and Garg, 2018), and most trials are small in sample size (mean=49) (Tromans and Adams, 2018). Furthermore, the literature on efficacy research is composed of more single-case-designs than group-designs of randomized controlled trials (RCTs) or quasi-experimental trials (Wong et al., 2015). From an evidence-based practice perspective, this results in mostly weak or insufficient evidence for treatment efficacy across commonly used, state-of-the-art early intensive behavioural interventions (EIBI), social skill groups, or parent-mediated early interventions (Table 1). In addition, few trials are able to show generalisation of intervention effects to wider contexts or long-term benefits (Green and 
Garg, 2018). Insufficient or weak evidence is also common for interventions considered 'alternative' (Table 1 and Panel 4). The trial literature is improving, owing to methodological progress, increasing use of RCTs and increased feasibility and accessibility implementation (Anagnostou, 2018, Green and Garg, 2018, Vivanti et al., 2018).

In group-designs, lack of blinding is particularly problematic but is difficult to resolve due to the nature of the interventions. The abundant single-case-designs likely reflect the diverse effort to address the needs of autistic individuals across different life stages and scenarios (but single-case-designs are by nature limited in terms of what can be concluded). This diversity may also reflect the heterogeneity of autism across multiple levels. With this in mind, it is important to ask two questions: Are there one-size-fits-all interventions that help most people with autism? To what extent can treatment or support reach the level of 'precision medicine' that is individualised (in terms of the individual's unique genes, environment and lifestyle backgrounds) and highly targeted (in terms of specific mechanisms of action) (Collins and Varmus, 2015)?

Despite increasing efforts to stratify autism at aetiological (Vorstman et al., 2017), neurobiological and phenotypic levels (Loth et al., 2017) towards the goal of greater precision (Loth et al., 2016), findings have yet to be translated into practice. Current clinical practice guidelines/recommendations developed by governmental or professional organizations rely on systematic reviews and expert panel discussion for intervention/support recommendations (eg, the UK National Institute for Health and Care Excellence (NICE) Clinical Guidelines (https://www.nice.org.uk/guidance/cg170, https://www.nice.org.uk/guidance/cg142) (Crowe and Salt, 2015, Pilling et al., 2012), the Swedish Agency for Health Technology Assessment and Assessment of Social Services Assessment (Swedish Council on Health Technology Assessment, 2013), or the American Academy of Child and Adolescent Psychiatry Practice Parameter (Volkmar et al., 2014)). They commonly take a holistic approach and emphasise that service providers should (1) receive training in autism awareness and management and ensure the individual and family's access to health and social care services; (2) support the individual and family to obtain behavioural/educational/psychosocial intervention (for children/youth) or vocational support (for adults), adjusted to the person's developmental level and 
individual needs to improve life skills, whilst acknowledging the overall limited evidence to date; (3) consider psychosocial/behavioural as well as pharmacological treatment for co-existing challenges such as anxiety, irritability, hyperactivity-inattention, or sleep disturbances, based on knowledge derived from the autistic population when available, or from the non-autistic population; (4) facilitate adjustment of the social and physical environment and process of care to meet individual needs; (5) support families and carers; (6) maintain an active role in long-term support, including life transition issues (eg, transition to adult services); and (7) improve the involvement of autistic individuals and their families in planning of their own support. The final point has been successfully adopted by recent initiatives of setting research priorities via the lived experiences of families and autistic individuals (also see Panel 2) (Frazier et al., 2018, Pellicano et al., 2014).

Considering (1) what we referred to earlier as the duality of autism, (2) the as yet low or insufficient evidence of specific interventions in helping core areas of disability in autism (Table 1), and (3) the substantial heterogeneity of individual needs, the model of care should be collaborative between clinicians, autistic individuals, their families and other key figures (eg, teachers, employers). This corresponds to shared decision-making (Elwyn et al., 2012). In particular, under the duality of autism framework there is a responsibility for clinicians to discuss with the stakeholders the question: does the target behaviour/symptom need intervention or is it better understood as part of neurodiversity?

Here we provide a review of the empirical literature of support for autistic people, taking a both-and stance to the duality of autism. We categorize current models into three complementary approaches with a developmentally sensitive, lifespan lens: (1) maximizing the potential of the individual, (2) minimizing barriers for the individual's development and adaptation, and (3) optimizing the person-environment fit (Figure 1). Other 'alternative' approaches are summarized in Panel 4. Although this article focuses on autism, it may also provide a template for planning support for people with other developmental disabilities.

Figure 1. A framework of supporting autistic people across the lifespan 


\section{Optimizing Person-Environment Fit}

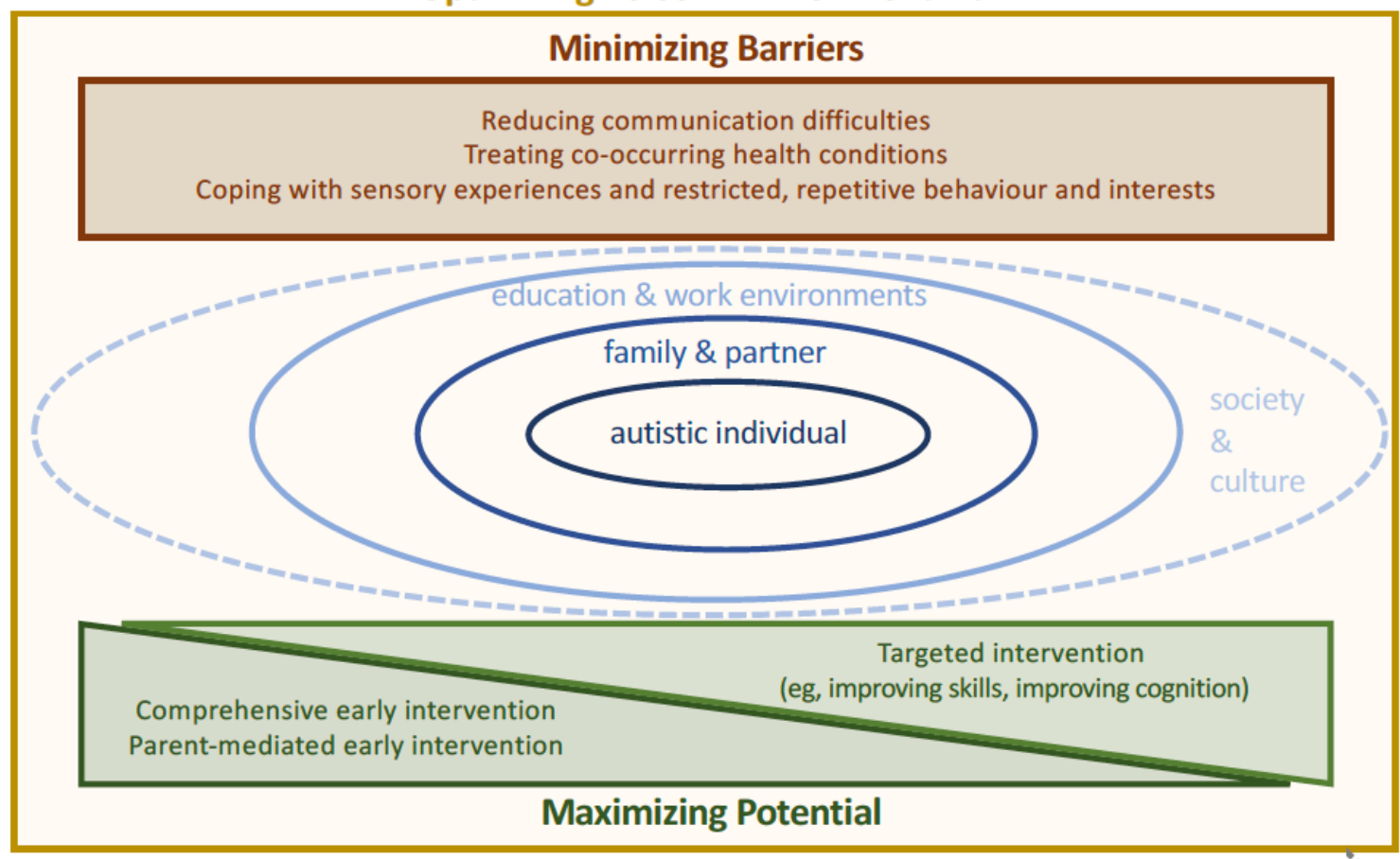

Tifespan Perspective

\section{Maximizing potential: Facilitating development and building skills}

Comprehensive early intervention (see Panel 3 for evolving perspectives)

Early Intensive Behavioural Intervention (EIBI) is the most studied early intervention model for autistic children. The latest Cochrane review shows that, based on one RCT and four non-randomized controlled trials (a total of 219 children) before 2017, with a low quality of evidence, EIBI improves autistic children's adaptive behaviour (mean differences [MD] on the Vineland Adaptive Behavior Scale (VABS) Composite, 9.58) yet change in autism characteristics was not significant. EIBI also improves IQ $(\mathrm{MD}=15 \cdot 44)$, expressive language (standardized mean differences, $\mathrm{SMD}=0 \cdot 51$ ) and receptive language $(\mathrm{SMD}=0 \cdot 55)$ (Reichow et al., 2018). A systematic review (commissioned by the U.S. Agency for Healthcare Research and Quality, AHRQ) on trials published after 2010 also reported that EIBI improves cognitive and language skills 
in some groups of young children, based on two RCTs, two non-randomized controlled trials, and six cohort studies, giving moderate strength of evidence but with varied magnitude of effects across studies, possibly due to poorly understood modifying characteristics of subgroups of autistic children (Weitlauf et al., 2014). Overall, EIBI might improve adaptation and developmental outcomes but does not seem to reliably alter core autism characteristics.

New trials included in the AHRQ review (Weitlauf et al., 2014) reflect progressing intervention models that have evolved away from the structured (traditional EIBI and Applied Behaviour Analysis, ABA) towards more naturalistic approaches (Prizant and Wetherby, 1998), namely Naturalistic Developmental Behavioural Intervention (NDBI) (Schreibman et al., 2015). Stimulated by research in developmental science and cognitive science of autism, NDBI models have incorporated developmental principles to reduce the discrepancy between highly structured ABA approaches (eg, discrete trial training, DTT) and principles of child development.

Increasingly, RCTs are being carried out for early intervention models. A recent systematic review of 48 RCTs (40 published since 2010) found the majority took an NDBI approach, JASPER (Joint Attention Symbolic Play Engagement and Regulation) being by far the most tested model by RCTs; nevertheless, even when blinding is overlooked, only $12.5 \%$ of RCTs met criteria of low risk of bias (French and Kennedy, 2017). Most common methodological concerns include lack of blinding of outcome assessment and failure to specify a method of allocation concealment. Also, although positive outcomes are significant in many trials (even at long-term follow-up beyond 2 years (Estes et al., 2015, Kasari et al., 2012)), they are mostly characterized by small effect sizes and wide confidence intervals. Substantial heterogeneity in sample characteristics, outcome measures, intervention models, dosage (intensity and duration of intervention), and a lack of understanding of the 'active ingredients', mediators and moderators of the oftentimes multi-component interventions, remain as the major methodological challenges for future trials.

\section{Parent-mediated early intervention}

An alternative or adjuvant form of early intervention is a parent-mediated approach, 
in which parents are trained by professionals to deliver support to their children. The concept of 'parents as co-therapists' has been included in several EIBI models, and the role of parental involvement is core to NDBI given the emphasis on naturalistic social interaction and ecological validity. Some involvement of parent training has been included in most early intervention models examined by recent RCTs (34/48) (French and Kennedy, 2017). A Cochrane review assessing the effectiveness of parent-mediated early intervention, based on 17 RCTs published by 2012 (Oono et al., 2013), reports no significant evidence of gain in most aspects of children's language and communication, children's initiation in parent-child interaction, children's adaptive behaviour, or parents' stress. The review reports positive changes in parent-child interaction patterns, especially in shared attention $(\mathrm{SMD}=0 \cdot 41)$ and parent synchrony $(\mathrm{SMD}=0 \cdot 90)$, alongside reduction of children's autism characteristics $(\mathrm{SMD}=-0 \cdot 30)$. There was suggestive evidence of parent-reported improvement in child language comprehension. However, the quality of evidence was all rated as low, mainly related to insufficient power of the RCTs, insufficient report of allocation concealment, incomplete outcome data, and variable blinding of assessors. Variability of outcome measures is a major concern. Similarly positive outcomes were reported in the single-case-design literature (Patterson et al., 2012). An updated systematic review and meta-analysis including 19 RCTs published until 2015 shows improved quality of evidence (mostly moderate) and benefit of parent-mediated intervention in reducing children's autism characteristics (Hedges' $\mathrm{g}=0 \cdot 22)$, improving language-communication $(\mathrm{g}=0 \cdot 16)$ and cognition $(\mathrm{g}=0 \cdot 24)$, but with very low quality of evidence supporting improvement in socialization $(g=0 \cdot 22)$, with no change in outcome with differences in dosage; most studies are however under-powered (Nevill et al., 2016).

Current evidence is still insufficient to guide the decision on the adequate proportion of parent-mediated vs. one-on-one therapists-guided interventions; this may vary depending on family contexts and child characteristics. Nevertheless, parent-mediated interventions have the potential to improve child development, parent-child interaction, and, particularly, parents' self-efficacy (Brian et al., 2017), not only facilitating autistic children's learning but also enhancing the person-environment fit from early in life. Parent-mediated interventions have been extended to 'at-risk' infants (ie, those who have an older autistic sibling) (Green et al., 2015) or those identified in regular community 
screening (Watson et al., 2017) by or before 12 months old. These approaches show potential to increase parents' responsiveness to infants and the infants' attention to parents, and reduction of infants' autism-related characteristics as well as changes in neurocognitive and neurophysiological indices (Jones et al., 2017a).

For children with confirmed diagnoses, evidence suggests positive long-term $(>2$ years) outcome in reduced clinician-measured autism characteristics (Green et al., 2017, Pickles et al., 2016). Parents can be trained via technology such as video feedback (Poslawsky et al., 2015) or remote tele-health or self-directed material (Parsons et al., 2017a, Rogers et al., 2012), therefore better suiting different family contexts and needs. Effectiveness has also been demonstrated for families in different cultural contexts beyond Western countries (Chiang et al., 2016, Rahman et al., 2016). Importantly, as early intervention can be expensive, time-limited (3-months) parent-mediated intervention has been shown to be helpful for low-resource US families in improving pre-schoolers' joint engagement and initiation of joint attention (Kasari et al., 2014b), showing promising accessibility.

Although more and larger RCTs are needed, current evidence indicates that early (before 3 years of age) provision of NDBI and active caregiver-involvement (eg, parent-mediated intervention) should be considered best practice for early intervention for children on the autism spectrum (Zwaigenbaum et al., 2015). To facilitate implementation across the globe, especially in low-resourced communities, the World Health Organization has also developed the WHO Parent Skills Training Package (http://www.who.int/mental health/maternal-child/PST/en/) to help caregivers support their children with developmental challenges, including autism.

\section{Targeted intervention}

When autistic children enter school, educational support becomes a major source of 'comprehensive' intervention to facilitate learning across multiple domains including daily living skills, literacy, math and other academic skills, organization and self-regulation, social interaction and collaboration. This is usually mandated by legislation in the region and provided in a variety of school settings (eg, mainstream/regular class, special education class, home-schooling) according to the 
child's needs, and via a regularly updated educational plan. For school-age autistic children (usually 5-18 years), targeted intervention (Lai et al., 2014, Wong et al., 2015) designed to address a relatively narrow but pivotal goal or set of skills with a fixed amount of sessions can be helpful for learning (Odom et al., 2012).

The first category of targeted intervention focuses on enhancing social skills and peer relationships. A Cochrane review for social skills groups (2-6 participants per group) for children and youth with autism (without intellectual disability) aged 6-21 years, based on five RCTs published before 2010, reports potential positive outcomes in improving overall social competence $(\mathrm{SMD}=0 \cdot 47)$, friendship quality $(\mathrm{SMD}=0 \cdot 41)$ and decreasing loneliness ( $\mathrm{SMD}=-0 \cdot 66)$ (Reichow et al., 2012b). There were no differences on related cognitive abilities (ie, emotion recognition or understanding of idioms). The quality of evidence was rated as low, particularly due to performance and detection bias. A meta-analysis of single-case-design studies also found improved social performance for children and youth with autism after receiving social skills intervention (Wang et al., 2013). Updated meta-analyses that include trials published after 2010 (eg, more RCTs based on the UCLA Programme for the Education and Enrichment of Relational Skills, PEERS $^{\circledR}$ ) further confirm that cognitively able autistic youth and adults benefit from group-based social skills training, demonstrated by improved social skills and wellbeing (Hotton and Coles, 2016, Spain and Blainey, 2015, Wolstencroft et al., 2018). However, the improvement varies by context and how performance is measured (Gates et al., 2017). Based on 19 RCTs, there is a moderate overall improvement in social competence when all measures are aggregated (Hedges' $g=0 \cdot 51$ ). The effects are the largest when assessed via self-report ( $g=0 \cdot 92)$, attributable to youth reporting having learned about social skills (social knowledge, $\mathrm{g}=1 \cdot 15$ ) rather than their perceived changes in their own social behaviour (social performance, $\mathrm{g}=0 \cdot 28$ ). The significant effects are larger for task-based measures $(\mathrm{g}=0.58)$ than parent-report $(\mathrm{g}=0.47)$ or observer-report $(\mathrm{g}=0 \cdot 40)$, but are non-significant for teacher-report $(g=0$-41) (Gates et al., 2017). In sum, group-based social skills training can be helpful in skill-building (particularly social knowledge and task-based performance) and potentially improves wellbeing for cognitively able autistic youth and adults. The remaining challenges are on actual social behavioural changes, flexibility of social behaviour, and generalizability to different contexts outside the group setting (eg, in the classroom or workspace) and over time (Jonsson et al., 2016). 
A second category aims at enhancing cognition (ie, social cognition and social-communication abilities) such as emotion recognition, joint attention, imitation, pragmatic language, and mentalizing. A Cochrane review based on 22 RCTs found a mix of interventions focusing on emotion recognition, joint attention, imitation, and mentalizing, resulted in mixed outcomes regarding changes of social, communication, and related cognitive skills, with low to very low quality of evidence (Fletcher-Watson et al., 2014). In domains that can be meta-analysed, teaching facial emotion recognition results in improved recognition of static facial emotions $(\mathrm{SMD}=0 \cdot 75)$, facilitating joint attention results in enhanced joint engagement during parent-child play ( $\mathrm{SMD}=0 \cdot 55)$; positive outcomes have also been reported in models on imitation and mentalizing (Fletcher-Watson et al., 2014). Across models, consistent drawbacks include a lack of generalisation of the target skill to novel settings or when measured in more complex and new scenarios, as well as unknown long-term benefits. Nonetheless, joint attention interventions for young children with autism (as incorporated in NDBI) appear to have the most consistent positive effects in improving children's joint attention initiation $(\mathrm{g}=0.47)$ and response $(\mathrm{g}=0.93)$, with maintained effects $(\mathrm{g}=0.56)$ (Murza et al., 2016) and potential of distal generalisation to other aspects of social-communication (Kasari and Patterson, 2012, Kasari et al., 2014c). When RCTs are selected based on the involvement of pragmatic language intervention (including joint attention training), a meta-analysis indicates an overall positive effect $(\mathrm{g}=0 \cdot 50)$ and, most importantly, the benefit does not seem to be restricted to pre-schoolers but also in children aged 6-12 years; notably, group-based intervention and those involving neurotypical peers appear to increase the effectiveness of intervention (Parsons et al., 2017b).

The literature also shows potentially positive outcomes of specific models, such as using Social Stories ${ }^{\mathrm{TM}}$ (ie, a narrative written for an autistic individual that describes a social situation and the behaviour expectations) to enhance social and play skills (Karkhaneh et al., 2010); using LEGO ${ }^{\circledR}$ Therapy (ie, leveraging the child's natural interest in activities such as $\mathrm{LEGO}^{\circledR}$, to motivate behavioural changes in social-communication such as verbal and non-verbal communication, initiation, turn-taking, sharing and collaboration) to enhance social-communication (Lindsay et al., 2017); using technology for human-computer interaction (eg, computer, interactive DVD, tablets, virtual reality) to enhance emotional recognition, language, social and academic 
skills (Grynszpan et al., 2014); and most recently, using social robots to facilitate learning (Pennisi et al., 2016). Many of these models do not require extrinsic rewards to capture the individual's attention and interest because they tap into the autistic individual's natural interests. More rigorous trials are needed to determine the effectiveness of these new targeted interventions. Conceptually they are promising as they leverage autistic individuals' strengths (eg, heightened systemizing (Baron-Cohen, 2008)) and interests (eg, in technology (Hedges et al., 2018)) to help acquire new skills. This is in line with the principles of NDBI for younger children or of structured teaching models, eg, the TEACCH (Treatment and Education of Autistic and related Communication handicapped Children) program, for a wider age range (Virues-Ortega et al., 2013).

\section{Developing pharmacological intervention for core autism characteristics}

Despite significant investments, no medications have been approved so far for core symptom domains in autism in any regulatory jurisdiction. This is not surprising given that selection of compounds for trials has only recently been informed by potential translational targets emerging from genomics, neurobiology and systems neuroscience (Green and Garg, 2018). However, the large number of potential targets resulting from the explosion of genomics and related scientific disciplines suggests that identifying the various biology associated with the different presentations of autism is critical in order to stratify individuals in subgroups with shared common biology likely to respond to a particular agent, as per the principles of precision medicine (Loth et al., 2016). Current evidence suggests that manipulation of excitation-to-inhibition (E:I) balance and neuropeptide targets may be promising candidates.

Altered signal-to-noise ratio due to E:I balance alteration has been proposed as a potential biological common pathway in at least a subgroup of autistic individuals (Rubenstein and Merzenich, 2003). Models based on some of the most common genetic causes of autism, such as Fragile X syndrome (Coghlan et al., 2012) and 15q11-q13 microduplication syndrome (Bassett, 2011), have documented changes in E:I balance. Attempts at manipulating E:I ratio have been made using both glutamatergic and GABAergic agents. Memantine, an uncompetitive NMDA inhibitor approved for patients with dementia, failed in a large RCT (despite early positive data) to impact the social 
symptoms of autism (Aman et al., 2017); another RCT is ongoing (NCT01972074). D-cycloserine, a partial agonist of the glycine $b$ site of the NMDA receptor, has however shown some promise for use as augmentation to social skills training at 22 weeks of treatment (Wink et al., 2017). Large RCTs of mGluR5 inhibitors failed to show effects on social function despite early promising human and animal studies (Berry-Kravis et al., 2016). Still, treatment of young children has not been evaluated adequately with these compounds. Early studies have also shown mixed results for riluzole, a compound affecting both presynaptic and postsynaptic glutamatergic transmission and glutamate release from glia, previously approved for treating amyotropic lateral sclerosis, with an RCT in children and youth pending (NCT01661855). Conversely, GABAergic manipulation has been attempted with arbaclofen, the $\mathrm{R}$ enantiomer of baclofen and a $\mathrm{GABA}_{\mathrm{B}}$ agonist. A large RCT was negative for social withdrawal (Veenstra-VanderWeele et al., 2017), but secondary analysis showed positive effects on socialization function as measured by the VABS. Finally, it is worth noting that changes in E:I balance and hence learning through long-term potentiation/depression (LTP/LTD) would likely require combination treatments of both agents targeting such pathways and learning interventions.

Oxytocin/vasopressin receptors have also been considered plausible targets of therapeutic manipulation as they are involved in social perception/cognition across species (Anagnostou et al., 2014a). Findings are mixed so far (DeMayo et al., 2017, Ooi et al., 2017). Small pilot RCTs showed some promise for effects on social cognition and potentially social-emotional wellbeing (Anagnostou et al., 2012) but follow-up smalland medium-sized RCTs have been inconsistent (Guastella et al., 2015, Parker et al., 2017, Yamasue et al., 2018, Yatawara et al., 2016), and some concerns have been raised regarding the long-term effects of oxytocin manipulation (Okamoto et al., 2016). Potential benefits, if they exist, may be contingent on a personalized design, considering the developmental stage, contextual factors, neurobiological characteristics including sex/gender, and adjuvant intervention (Guastella and Hickie, 2016). Several larger RCTs of oxytocin and vasopressin are ongoing (eg, NCT01944046, NCT01788072, NCT01962870, NCT02901431). A phase III RCT (NCT03504917) for adults using balovaptan, a vasopressin 1a receptor antagonist, is starting in North America and Europe, following a positive phase II RCT (NCT01793441) showing potential in improving social 
interaction and communication; a phase II RCT of this compound for children and youth is ongoing (NCT02901431). Similar to compounds affecting E:I balance, compounds that may enhance social learning may also require combination trials of such agents and social learning interventions (eg, NCT02918864).

Altered serotonin mechanisms and increased serotonin blood levels have been reported in subgroups in the autistic population; reciprocal interactions between serotonin and other neuropeptides, including oxytocin, may be particularly important for social behaviour (Muller et al., 2016). A large RCT of buspirone in the 2-6 year-old population showed no difference in the total ADOS score but reduction in the restricted and repetitive behaviour score on $2.5 \mathrm{mg}$ daily (Chugani et al., 2016). Whether this effect can be further enhanced with concomitant behavioural interventions needs to be investigated.

\section{Is there a Holy Grail to maximizing potential?}

Comprehensive early intervention may help autistic children's early development of adaptive, cognitive and language skills. Parent-mediated approaches have many potentials and benefits over the reliance only on intensive therapist-delivered intervention. A naturalistic approach (ie, NDBI) may bring developmental trajectories more aligned with typical development, and consequently, the social-communication behaviours may be more natural/intuitive than those learned in a rote way via highly structured ABA approaches.

This is critical as when skills are facilitated/taught at a later age (eg, school age or beyond), via targeted approaches, they seem to be acquired via alternative cognitive routes. They can still be adaptive in specific contexts but are more controlled (reflective) than automatic (intuitive) and can be inflexible and rote, as shown by current findings, ie, knowing does not necessarily lead to enacting, and generalisation of the trained skills to related domains or other contexts is consistently challenging. This conclusion may lead to the view that 'the earlier the better' is the principle for intervention, to facilitate skill building. Such principles may apply to children diagnosed early in life and with delayed development and adaptation. Nonetheless, for many on the milder end of the autism spectrum, the need for diagnosis and intervention may be dynamic, contingent on the individual's developmental path and the person-environment fit at that time. There can be 
multiple ways to achieve adaptation, some via genuine remediation but others via deep or shallow compensation mechanisms (Livingston and Happe, 2017).

To this end, individualized planning of support should be the principle across developmental stages, although the evidence-base is still scant for a precision medicine approach. Shared decision-making and collaborative support planning are recommended, based on the principles of respecting agency and individual differences, whilst enhancing adaptation and alleviating distress.

\section{Minimizing barriers: Reducing concurrent difficulties}

\section{Reducing communication difficulties}

Enhancing verbal and non-verbal communication is an integral part of comprehensive early interventions, and is core to parent-mediated approaches, eg, the Preschool Autism Communication Trial (PACT) (Green et al., 2010, Pickles et al., 2016). Yet, despite years of early intervention, there is still a portion of autistic children who produce little expressive (spoken) language by school-age (ie, 5 years-old). These 'minimally verbal' children (Tager-Flusberg and Kasari, 2013), maybe about 30\% of all autistic children, do not necessarily have low receptive language or non-verbal intellectual abilities. They often show floor effects on standardized direct assessments, which may be an underestimation of their true cognitive potential (Courchesne et al., 2015), thus requiring modified assessment and new measures to reflect their unique strengths and weakness (eg, non-verbal receptive and expressive communication, non-verbal intelligence) (Kasari et al., 2013). Efforts have been made to extend NDBI into this population, and initial evidence suggests that including augmentative and alternative communication systems (eg, devices for non-speech means for expressive and receptive communication, tablets) may bring better outcomes across domains (Aspiranti et al., 2018, Iacono et al., 2016, Morin et al., 2018, Tager-Flusberg and Kasari, 2013).

A conventional 'low-tech' system, the manualized Picture Exchange Communication System (PECS), trains the minimally verbal child to use specific pictures for request and 
commentary as ways of functional communication. A meta-analysis finds this approach increases functional communication using PECS and it neither inhibits or facilitates spoken language development (Flippin et al., 2010). The use of speech-generating devices (eg, using a mobile device with communication applications) is superior to PECS or manual sign language for minimally verbal autistic individuals in increasing their requesting repertoire, although the effects on non-requesting functional communication and spoken language remain unclear (Lorah et al., 2015). Recent RCTs show that incorporating speech-generating devices into NDBI (ie, JASPER plus Enhanced Milieu Teaching) increases spontaneous verbal (spoken) communication beyond requesting and communication interchanges in school-age minimally verbal autistic children (DiStefano et al., 2016, Kasari et al., 2014a).

Assistive technology has the potential to minimize communication barriers not only for minimally verbal individuals but also for others on the autism spectrum (Chandler, 2016) (also see:

\section{https://www.autismspeaks.org/family-services/resource-library/assistive-technology).}

Although the exact benefits and drawbacks of incorporating augmentative and alternative communication in comprehensive early intervention or targeted intervention at later ages (eg, social skills training) are still unclear (Iacono et al., 2016), advancing technology has potential in minimizing barriers of learning and development and should be incorporated and rigorously examined in future trials.

\section{Treating co-occurring health conditions}

Across the lifespan, autistic individuals have a higher probability than people in the general population to have other health conditions (Davignon et al., 2018, Kohane et al., 2012, Muskens et al., 2017, Soke et al., 2018, Weiss et al., 2018), likely due to shared biological causes and/or the experiences of living with autism (Lai et al., 2014, Vorstman et al., 2017). Common co-occurring neurodevelopmental challenges include intellectual disability, attention-deficit/hyperactivity disorder (ADHD), tic disorders, learning disorders (Lundstrom et al., 2015) and genetic anomalies (Richards et al., 2015, Vorstman et al., 2017). Most common physical conditions include epilepsy (Bolton et al., 2011, Jokiranta et al., 2014), immunological disorders (eg, atopy), gastrointestinal (eg, 
constipation) and sleep problems (Bauman, 2010, Croen et al., 2015, Jones et al., 2016, Kohane et al., 2012, Muskens et al., 2017). Most common mental health issues include anxiety, irritability, self-injurious behaviour, obsessive-compulsive disorder, mood disorders (including depression), suicidal risk, eating disorders, and psychotic disorders (Howes et al., 2018, Lai et al., 2014). In many scenarios, impaired 'emotion regulation', possibly associated with the atypical neurobiology of autism, and the absence of autism-friendly environments, may be a more parsimonious explanation than multiple co-occurring psychiatric diagnoses (Mazefsky and White, 2014). We should keep in mind that the above conditions are closely entwined, with shared underpinning mechanisms (Brainstorm et al., 2018, Vorstman et al., 2017).

Co-occurring health conditions have a negative impact on wellbeing (Helles et al., 2017, Lin and Huang, 2017) and can even increase mortality risk (Schendel et al., 2016). Therefore, alleviating such challenges across the lifespan is an integral part of care. It is important that autistic people have primary care providers who understand autism and the associated cognitive, communication and social issues, can identify common co-occurring health conditions and their potential complications (eg, obesity), can help with decision-making, can identify when violence and abuse is directed towards the individual, and can make referrals to specialists (eg, psychiatry, neurology, gastroenterology) (for online resources see: https://autismandhealth.org) (Nicolaidis et al., 2014, van Schalkwyk and Volkmar, 2017). Specifically, whilst the paediatric neurologist is usually comfortable with working with the autistic population, there should be a plan for a smooth and efficient transition to an adult provider at an appropriate age (Brown et al., 2016). The adult neurologist should know what is needed for effective care delivery for autistic adults, including factors affecting interaction, communication, behaviour, and compliance, for evaluation, testing, and with prescribed treatments (Devinsky et al., 2015, Nicolaidis et al., 2014).

In current practice, there is considerable use (and risk of overuse) of psychotropics, especially antipsychotics, stimulants, antidepressants, and their combinations, in the autistic population, with a median prevalence of $45 \cdot 7 \%$ (Jobski et al., 2017, Park et al., 2016). However, evidence-based clinical guidelines for treating co-occurring conditions in autism are often unavailable due to insufficient RCTs. In such scenarios, clinicians 
should follow guidelines developed for the general population and modify care based on specific needs of the autistic individual. An extensive discussion of specific treatments is beyond the scope of this review; readers are encouraged to refer to dedicated reviews (Ameis et al., 2018, Anagnostou, 2018, Howes et al., 2018) and the citations in the following paragraphs for details.

Several guidelines/recommendations suggest routine clinical genetic testing (ie, chromosome microarray, G-banded karyotyping, fragile $\mathrm{X}$ syndrome testing) (Anagnostou et al., 2014b, Kearney et al., 2011a, Kearney et al., 2011b, Manning et al., 2010, Shen et al., 2010) or even whole-genome sequencing in the foreseeable future (Tammimies et al., 2015). The results can inform surveillance of health issues, family genetic counselling, with potential to lead to precision medicine (Vorstman et al., 2017). Assessment and treatment of epilepsy should follow best practice pathways in the general population (https://www.nice.org.uk/guidance/CG137), and this is the same for immunological (eg, https://www.nice.org.uk/guidance/cg57) and other medical conditions. There is a lack of trials of anti-epileptic medication for seizure in autistic individuals (in contrast to trials targeting behavioural issues (Hirota et al., 2014)) to guide a specific treatment protocol, hence management should follow the same principles as in the non-autistic population (Tuchman et al., 2013). Evaluation of gastrointestinal problems in autistic individuals should be thorough and standard, especially noting that 'problem' or 'challenging' behaviour may be the sole or primary manifestation of medical causes including gastrointestinal problems (Buie et al., 2010a); an adaptation of general paediatric guidelines has been provided (Buie et al., 2010b). Assessment of sleep problems (eg, insomnia) should always include medical contributors and sleep hygiene, and when a behavioural approach is not successful, melatonin could be considered (Howes et al., 2018, Malow et al., 2012).

Management of irritability and 'problem/challenging' behaviour must start by eliminating potential contributors (eg, physical or mental health problems, communication difficulties, psychosocial issues, environmental changes). This point is of central importance, since there is a risk that psychosocial approaches are stopped too early in favour of a quick-fix medication, instead of exploring the factors behind symptoms such as irritability or anxiety. If addressing contributing factors is not 
sufficiently effective, a recent guideline (McGuire et al., 2016) suggests that clinicians could consider pharmacological intervention: in higher-risk scenarios with aripiprazole or risperidone (based on established evidence from multiple RCTs but with substantial risk of persistent adverse effects) and in lower-risk scenarios, clonidine or $\mathrm{N}$-acetylcysteine (based on initial evidence from single pilot trials and with low evidence of associated harms) (Fung et al., 2016, McGuire et al., 2016). If long-term use of aripiprazole or risperidone is indicated, common side effects (eg, somnolence, weight gain, extrapyramidal symptoms) must be monitored and managed (Ameis et al., 2013). An initial RCT suggests metformin has a modest effect in decreasing weight gain associated with the use of atypical antipsychotics (Anagnostou et al., 2016, Handen et al., 2017).

ADHD symptoms, particularly hyperactivity, can be treated with methylphenidate (and potentially other stimulants), atomoxetine or guanfacine (and potentially clonidine), supported largely by RCT-based evidence (Howes et al., 2018, Mahajan et al., 2012, Sturman et al., 2017), but side effects may be more frequent or severe than in individuals with ADHD without autism, including aggravation of anxiety (Howes et al., 2018). Regarding anxiety symptoms, although selective serotonin reuptake inhibitors (SSRIs) or other antidepressants have shown efficacy in non-autistic populations of different ages, there is still a lack of evidence to support similar efficacy in reducing autism-specific anxieties (eg, adherence to routine and fear of uncertainty, sensory overload); they might have better chance in reducing typical anxieties with the same characteristics as in the non-autistic population (eg, generalized anxiety, social anxiety, separation anxiety), especially when there is a positive family history of similarly typical anxieties, yet this requires further empirical investigation. Instead, modified cognitive-behavioural therapy (CBT) is promising in reducing anxiety in the autistic population (Weston et al., 2016). If an SSRI is to be prescribed, clinicians need to start with a low dose, exercise caution and watch for the known higher risk of behavioural activation side effects (eg, increased energy/activity, impulsivity, disinhibition, insomnia) (Vasa et al., 2016).

Increased suicidal risk has been reported in autistic youth and adults across different countries (Cassidy and Rodgers, 2017, Chen et al., 2017, Segers and Rawana, 2014, Zahid and Upthegrove, 2017) and should be assessed with a view to intervention. Self-injurious behaviours are common, especially in those with intellectual disabilities, 
and may be associated with higher levels of stereotyped behaviour, impulsivity, sleep disorder, anxiety and pain processing. Their causal roles require clinical attention as these may influence the choice of intervention (Oliver et al., 2017). Reports of treatment for catatonia in autism include electroconvulsive therapy, various medications and behavioural or sensory approaches, but all of these are based on single-case-designs or case-series, with extremely limited evidence of efficacy. Early intervention may be beneficial, and electroconvulsive therapy, high-dose lorazepam and behavioural interventions may have short-term benefits (DeJong et al., 2014). Adolescents with first-episode psychosis and underlying autism are less likely to have a beneficial response to antipsychotics compared with those without autism (Downs et al., 2017), suggesting a greater therapeutic challenge in autistic people.

Overall, there is little evidence evaluating pharmacological treatment of psychotic disorders, depression, bipolar disorder, and obsessive-compulsive disorder, despite their greater occurrence in the autistic population. There are also too few treatment trials focusing on transition-age youth and adults' health concerns (Dove et al., 2012). Clinical decisions are often made based on the clinician's experience and extrapolation from trials in autistic children and youth or in non-autistic individuals. Further validation is therefore needed. Until there is evidence that pharmacological management should differ from those in the non-autistic population, a similar decision-making process as in the general population should be considered best practice. However, as in the wider population with developmental disabilities, we may expect a higher sensitivity to adverse effects of psychotropic medications. Therefore, medication should be prescribed with caution and with clear targets, following the principle of 'start low, go slow, and watch for behavioural activation and side effects.'

There are also limited prospective longitudinal studies examining the risk and protective factors for health concerns across the lifespan, but available studies suggest within-family (parental) stress (Simonoff et al., 2013, Zaidman-Zait et al., 2014) and autistic individuals' adverse experiences (eg, bullying, or being rejected) (Cage et al., 2018, Hoover and Kaufman, 2018) predict poorer health and functional outcomes. Enhancing the individual's ability to cope with stress and reducing unhelpful stress load should be integral to minimizing health challenges and enhancing resilience in autistic 
individuals (Lai and Baron-Cohen, 2015, Szatmari, 2018). A promising avenue is the use of mindfulness-based stress reduction in autistic individuals, for which initial data suggest a positive impact of reducing anxiety, depression and rumination and enhancing wellbeing across individuals of different ages (Cachia et al., 2016).

Coping with sensory experiences and restricted, repetitive behaviour and interests (RRBI)

Sensory issues, involving perceiving, integrating and modulating responses to daily sensory stimuli across various domains, are commonly experienced by autistic individuals, with changes over development (Schaaf and Lane, 2015). Although some may be soothing and self-regulating (eg, sensory-seeking or interests), others might be challenging or maladaptive (eg, idiosyncratic responses, hyper-responsivity, aversive responses). Sensory over-responsivity is particularly associated with anxiety in autistic individuals (Mazurek et al., 2013). Alleviating sensory-related challenges has been a focus of occupational therapy, stemming from a mix of theoretical approaches. A recent AHRQ systematic review based on 24 studies (20 RCTs) found limited, potentially short-term ( $<6$ months) benefits for certain approaches, but all with low strength of evidence (Weitlauf et al., 2017): (1) sensory integration improved sensory and motor skills-related measures; (2) environmental enrichment (of sensory stimuli to promote tolerance) improved nonverbal cognitive skills; (3) massage improved autistic symptom severity and sensory challenges; yet (4) auditory integration-based approaches did not improve language (also shown in an earlier Cochrane review (Sinha et al., 2011)). Overall, more sensory-related research in autism is needed, to guide the development of rigorously tested interventions tailored to the multi-dimensional, multi-model sensory characteristics of each individual (Uljarevic et al., 2017).

Not all RRBI need treatment/intervention, but some do. Akin to sensory experiences, many ego-syntonic RRBI can be soothing, anxiety-relieving and self-regulating, or a reflection of the individual's learning style (eg, 'stimming', narrow interests) (Koenig and Williams, 2017), whereas others may be challenging if they contravene ordinary social-contextual expectations or interfere with the individual's ability to cope and function. Understanding the function of RRBI is the essential step to support an autistic individual, rather than treating RRBI as the sole target to be reduced (Mottron, 2017). 
'Problematic' RRBI may reduce as a collateral effect when social-communication is facilitated, or stress-level reduced; for example, repetitive movements can be an epi-phenomenon of underlying anxiety, which can be reduced if well supported (Boyd et al., 2012). For autistic adults, an optimal amount of special interests has positive impacts and is associated with higher subjective wellbeing and satisfaction across life domains including social contact and leisure (Grove et al., 2018). Narrow interests, preoccupation, repetition and their plausible underlying cognitive bases (eg, focused attention, attention to detail, hyper-systemizing, weak central coherence) have the potential to support social-communication skill building (Koegel et al., 2013, Mesibov and Shea, 2010) and personal achievement (Baron-Cohen et al., 2009, Happe and Vital, 2009).

There is still insufficient research treating RRBI as the primary outcome (Harrop, 2015) and a lack of evidence showing reduction of RRBI by psychosocial interventions (see https://www.nice.org.uk/guidance/cg170) or medications such as SSRIs (Carrasco et al., 2012, Williams et al., 2013). The effect of SSRIs on ego-dystonic RRBI or co-occurring OCD symptoms is not yet established (eg, potential benefits are reported for adults but not children) and deserves further investigation (Williams et al., 2013). Initial studies suggest CBT might also be promising (Kose et al., 2018). Although trials of risperidone and aripiprazole showed small reduction of 'compulsion' as a secondary outcome (Marcus et al., 2009, McCracken et al., 2002), risk of harm must be carefully weighed against benefits in clinical decision-making.

\section{Optimizing person-environment fit: enhancing adaptation and making reasonable adjustments to the environment}

Adaptation is in part a function of the interaction between an individual and their environmental context. Adequate support for autistic individuals must go beyond targeting the individual and should include contextual factors. Support should be dynamic across the lifespan as adaptation issues and contexts are different in childhood (eg, educational support) vs. adulthood (eg, residential and vocational support). The idea of enhancing the person-environment fit by creating supportive and autism-friendly contexts (Lai and Baron-Cohen, 2015) has been included in several approaches reviewed above. 
For example, TEACCH aims at enhancing learning by structuring the environment based on autistic individuals' strengths and weakness (Mesibov and Shea, 2010); parent-mediated early interventions and other 'train-the-trainer' models (Shire and Kasari, 2014) often involve adjusting the physical environment to increase the child's initiative (Schreibman et al., 2015), and increasing parental sensitivity and responsiveness to child communication to create a more fine-tuned caring environment for their development (Green et al., 2010). Improved person-environment fit entails increasing the autistic person's sense of control and environmental predictability, whilst allowing for flexibility that is necessary in educational or work environments. To achieve these, support should aim at facilitating adaptation, and care for autistic individuals should take a collaborative, shared decision-making approach. Optimizing the person-environment fit should be an $a$ priori consideration for all support/intervention strategies across the lifespan.

Care for families of autistic individuals is essential for creating a supportive environment. Although the literature for family (systemic) intervention to enhance communication, relationships or coping is lacking (Spain et al., 2017), initial trials have shown promising effectiveness of mindfulness-based stress reduction, positive psychology approaches, and problem-solving education for parents of autistic individuals in reducing their own stress, anxiety and depressive symptoms (Dykens et al., 2014, Feinberg et al., 2014, Lunsky et al., 2017). Family-systems oriented support is crucial in all clinical practice, but more studies are needed to identify the 'active ingredients' of this support and how the wellbeing of all parties in the family can be improved, eg, by reducing misunderstandings (Heasman and Gillespie, 2017) and enhancing communication and coherence.

Peer influence is particularly related to the wellbeing of autistic children and youth. Non-autistic adults often have a negative first impression of autistic adults, which is associated with reduced motivation to pursue social interaction with them (Sasson et al., 2017). However, a better understanding of autism is associated with non-autistic peers' better impression of the autistic individuals (Sasson and Morrison, 2017). This suggests that improving autism knowledge in non-autistic peers has the potential to improve the social wellbeing of autistic individuals. Initial evidence shows school-based peer-mediated intervention (eg, teaching peers autism knowledge and skills to support 
autistic individuals) (Chang and Locke, 2016, Sutton et al., 2018, Whalon et al., 2015) and involving siblings in existing intervention (Shivers and Plavnick, 2015) lead to better functioning and improved outcomes for autistic individuals (eg, increasing frequency and duration of initiating and responding behaviours during peer interaction). Inclusion in education is essential but still largely unmet, primarily due to inadequate attitudes and practice instead of insufficient formal regulations (Pellicano et al., 2018).

Preparing for employment and finding an appropriate job is critical but challenging for transition-age youth and adults with autism. Supported employment (eg, community placement and job coaching) and technology/media-based support (eg, practicing a job interview) are potentially beneficial for vocational outcomes for autistic individuals (Nicholas et al., 2015). Vocational fit and success does not solely depend on skill-building of the autistic individual, but is also closely linked to community resources, family support, workplace capacity building (for employers and co-workers), advocacy and policy (Nicholas et al., 2018). Increasing initiatives taking an ecosystem approach based on private-public partnership are developing (see http://worktopia.ca/ and http://usbln.org/what-we-do/autism-employer-roundtable/). Societies around the globe need to recognize that improving vocational success for autistic individuals is beneficial for all, considering both inclusion and economic (cost-benefit) standpoints (Jacob et al., 2015).

Finally, autistic individuals and their family also tend to experience stigma, which significantly contributes to life difficulties (Broady et al., 2017, Johnson and Joshi, 2016, Kinnear et al., 2016). Stigmatization can be particularly promoted through the media (Brewer et al., 2017, Holton et al., 2014, Huws and Jones, 2011, Tang and Bie, 2016). Programs reducing stigma associated with autism implemented in the school setting (Gillespie-Lynch et al., 2015, Ranson and Byrne, 2014, Staniland and Byrne, 2013) or through the media (eg, the 'Sesame Street and Autism' initiative, http://autism.sesamestreet.org/) are promising and much needed. 


\section{Future development}

From an evidence-based perspective, more well-powered, robustly designed RCTs examining both benefits and harms are needed for all approaches summarized above, to improve the quality of evidence and to establish clinical guidelines. This is necessary, but not sufficient, for improving the support/intervention literature. One fundamental issue remains: due to the substantial clinical, biological and aetiological heterogeneity, it is unlikely that there is one 'silver bullet' for all individuals. Stratification approaches (ie, at a subgroup level) via both 'supervised' and 'unsupervised' methods will be critical for future trials to guide the eventual development into precision intervention (ie, at an individual level) (Loth et al., 2016).

From the 'supervised' (ie, hypothesis-driven subgrouping) angle, it is still an unanswered empirical question regarding how intervention/support should be tailored to the individuals' varied developmental trajectories of language, communication, intellectual and adaptive functioning (Georgiades et al., 2017). This may also be true for cognitive characteristics (Brunsdon and Happe, 2014). For example, we do not know enough about the moderators and mediators for effectiveness of NDBI (eg, how skill-building can be more individualized) (Schreibman et al., 2015), and neither do we know how targeted social skills building approaches can be amended (eg, in conjunction with augmentative and alternative communication) for autistic individuals with insufficient expressive communication skills. Sex and gender account for important heterogeneity in autism from phenotypes to aetiologies (Lai et al., 2015). Although some intervention trials have not identified sex or gender as a key moderator to outcomes (McVey et al., 2017), this is still inconclusive due to small samples of females in the trial literature, resulting in insufficient power to examine sex-moderating effects. There is a need for evidence to develop sex- and gender-informed support for autistic individuals across all sexes, genders and sexualities. Meanwhile, at the neurobiological level, there is initial evidence that baseline brain activities when perceiving biological motion predict PRT intervention outcome (Yang et al., 2016). This example illustrates a promising new avenue of neurobiology-guided intervention. On the other hand, 'unsupervised' (ie, hypothesis-free subgrouping) approaches that use big data across measurement levels have potential to identify latent subgroups (Lombardo et al., 2018) even cutting across 
DSM/ICD-based diagnostic boundaries (Stefanik et al., 2018) and guiding neurobiology-informed interventions on key constructs underlying the diagnostic labels.

There are several directions that are relatively under-developed, especially considering the duality of autism and ways to enhance person-environment fit. These include: (1) lifespan support for transition-age and healthy aging; (2) individual- and family-based support for family relationships, self-identity development, adverse experiences and developmental trauma, and intimate (romantic) relationships; (3) systems-level support for autism-friendly and developmental disability-friendly environments; (4) practical implementation of resilience-based and strengths-based approaches; and (5) culturally sensitive support and interventions in the global context. New cognitive enhancing and skill-building models that go beyond the social domain and address executive dysfunctions are developing, but these need to be tested by RCTs (Eack et al., 2017). New medical interventions whose target is to enhance skill building and mitigating barriers for adaptation is progressing (eg, neuromodulation to improve executive function or social cognition (Oberman et al., 2016)) and should be integrated with stratification approaches.

The ultimate goal for any support/intervention is to enhance the person's wellbeing. To achieve this, support should be holistic, for both the individual and their context. The duality of autism should not be viewed as opposing perspectives of whether autism is a disorder to be treated or a variant of human nature to be cherished. When both the identity and disability of autism are recognized and embraced (Silberman, 2015, Solomon, 2012), it becomes clear that enhancing adaptation and wellbeing is the common ground. This needs to be achieved through collaboration and joint effort across autistic individuals, families, service providers, policy makers and advocacy. 


\section{Search strategy and selection criteria}

We searched PubMed for systematic reviews, meta-analyses, guidelines and other reviews published until June 30, 2018, using the search terms "autis* AND (intervention OR treatment)". We then supplemented our reference list by searching the reference list of the identified reviews, and other relevant empirical papers and publications. We selected papers published in English. The final reference list was generated based on the relevance to the topics covered in this review, to synthesize most updated empirical findings and remaining challenges regarding support and intervention for individuals with autism.

\section{Contributors}

All authors conceived the framework of review, contributed to the writing and approved the final manuscript. M-CL performed the literature review and drafted the first version of manuscript.

\section{Declaration of interests}

M-CL, CA and SB-C declare no competing interests. EA has received consultation fees from Roche, Takeda, and in-kind contributions from AMO pharma, royalties from APPI, and editorial honoraria from Wiley. MW has received payments for consultation/testimony for legal proceedings involving autism diagnosis.

\section{Acknowledgments}

We would like to thank Caroline Kassee for assistance in creating Table 1, and Peter Szatmari, Stephanie H. Ameis and Yona Lunsky for valuable discussions during the preparation of this work. M-CL is supported by the O'Brien Scholars Program within the Child and Youth Mental Health Collaborative at the Centre for Addiction and Mental 
Health (CAMH) and The Hospital for Sick Children, Toronto, the Academic Scholars Award from the Department of Psychiatry, University of Toronto, the Slaight Family Child and Youth Mental Health Innovation Fund and The Catherine and Maxwell Meighen Foundation (both via CAMH Foundation), and the Ontario Brain Institute via the Province of Ontario Neurodevelopmental Disorders (POND) Network. EA is supported by funding from CIHR, NIH, DoD, Ontario Brain Institute, Brain Canada, Genome Canada, Ontario Research Fund, Azrieli Foundation, Autism Speaks, HRSA, Canada Research Chairs Program, and Dr. Sims Chair in Autism. SB-C and CA are supported by the Autism Research Trust, Autistica, UK Medical Research Council, and by the National Institute for Health Research (NIHR) Collaboration for Leadership in Applied Health Research and Care East of England at Cambridgeshire and Peterborough NHS Foundation Trust; the views expressed are those of the authors and not necessarily those of the NHS, NIHR or Department of Health and Social Care. 


\section{Panels}

\section{Panel 1. Autism as both a medical condition and an example of neurodiversity}

Autism was first described and defined in the clinical literature in the first half of the $20^{\text {th }}$ century as a medical condition with an onset in early childhood (Asperger, 1944, Kanner, 1943, Ssucharewa and Wolff, 1996, Van Drenth, 2018). Substantial cognitive potential and plausible contribution to society ('social value') have been articulated in Leo Kanner and Hans Asperger's initial reports (Asperger, 1944, Kanner, 1943), with the appreciation that the persistence of characteristics implies a 'personality type' already evident in childhood (Asperger, 1944, Ssucharewa and Wolff, 1996). However, in the subsequent decades autism was largely viewed as a medical disorder, psychological disturbance, and then a cluster of neurodevelopmental diseases to be treated, similar to other medical disorders defined nowadays (Feinstein, 2010, Silberman, 2015). This is highly associated with the marked difficulties in development and adaptation that these people have experienced. With the recognition of autism as a spectrum (Wing, 1975), the broadening of the diagnostic boundary, and the recognition that autistic characteristics are continuously distributed in the general population (Constantino and Charman, 2016), more individuals are recognized being 'on the autism spectrum' at later and different stages of life (Lai and Baron-Cohen, 2015). The view that autism is part of a neglected or marginalized part of typical variation of human beings emerged around the beginning of the $21^{\text {st }}$ century. This 'neurodiversity' view posits that the brains of autistic individuals (as well as others with neurodevelopmental disorder labels such as ADHD or dyslexia) are differently wired, with different versions of 'human operating system'. The neurodiversity view critically asserts that differences do not necessarily lead to disability ("Just because a computer is not running Windows doesn't mean that it's broken.") (Silberman, 2015). Although there can be disagreements when it comes to intervention/treatment (as per the medical disorder view) or understanding/support (as per the neurodiversity view), we hold the view that adequate support for autistic individuals require both perspectives. The aim of intervention is not to eradicate or prevent autism, but to improve adaptation and reduce disability, which necessarily 
involves the autistic individual (ie, to maximize their potential and minimize barriers for development and wellbeing) and changes to the environment (ie, to enhance the person-environment fit). Leveraging autistic characteristics to enhance learning is included in many mainstream interventions, eg, NDBI (Schreibman et al., 2015) and TEACCH (Mesibov and Shea, 2010). The creation of inclusive and autism-friendly sensory, physical and social environments requires ongoing effort and collaboration across parties. Scientific inquiry into novel evidence-based support to foster autistic strengths is still needed (Mottron, 2017). For example, Hans Asperger pointed out in his seminal case series that 'autistic intelligence' involves substantial originality, and that the 'special abilities and disabilities of autistic people are interwoven' (p.70) (Asperger, 1944/1991). Support for people on the autism spectrum should acknowledge both strengths and disabilities and respect individual differences.

Panel 2. Examples of priority setting for research to improve health and wellbeing for individuals with autism

Example 1. Canada: Ontario Brain Institute's Priority Setting Partnership for research priorities

“Top 10 Research Priorities for Neurodevelopmental Disorders" (http://braininstitute.ca/programs-opportunities/setting-research-priorities/neurodevelopm ental-disorders-psp):

1. What are the most effective treatment options/plans (eg, timing, frequency, duration, type, intensity or dosage) for individuals with neurodevelopmental disorders for both short and long-term benefits?

2. How can system navigation be organized in a manner that enables coordinated services and supports across the lifespan for individuals with neurodevelopmental disorders and their families?

3. Which biological treatments (including medications, gene therapy, stem cell therapy, etc.) are effective for neurodevelopmental disorders and associated symptoms? 
4. Which child and family-centred interventions or approaches promote optimal individual and family functioning?

5. Which interventions best help individuals with neurodevelopmental disorders develop emotional and behavioural regulation (including increasing impulse control and reducing compulsive behaviour)?

6. Which resources are needed to more effectively address the health, social and emotional needs of families or caregivers of individuals with neurodevelopmental disorders?

7. How can treatment decisions for individuals with neurodevelopmental disorders be more precise (ie, based on the diagnosis, age, functional need of the individual)?

8. Which are the most effective pharmacological and non-pharmacological treatments for aggressive and self-injurious behaviour in individuals with neurodevelopmental disorders?

9. Which are the most effective pharmacological and non-pharmacological intervention(s) to reduce anxiety in individuals with neurodevelopmental disorders?

10. Which interventions are most effective to help individuals with neurodevelopmental disorders improve their social skills and develop and maintain social relationships?

Example 2. UK: Autistica's partnership with stakeholders in identifying most pressing questions about autism and mental health

"Your top ten questions for autism research"

(https://www.autistica.org.uk/our-research/our-research/your-research-priorities)

1. Which interventions improve mental health or reduce mental health problems in autistic people? How should mental health interventions be adapted for the needs of autistic people?

2. Which interventions are effective in the development of communication/language skills in autism?

3. What are the most effective ways to support/provide social care for autistic adults?

4. Which interventions reduce anxiety in autistic people? 
5. Which environments/supports are most appropriate in terms of achieving the best education/life/social skills outcomes in autistic people?

6. How can parents and family members be supported/educated to care for and better understand an autistic relative?

7. How can autism diagnostic criteria be made more relevant for the adult population? And how do we ensure that autistic adults are appropriately diagnosed?

8. How can we encourage employers to apply person-centred interventions \& support to help autistic people maximise their potential and performance in the workplace?

9. How can sensory processing in autism be better understood?

10. How should service delivery for autistic people be improved and adapted in order to meet their needs?

\section{"5 ways to transform mental health in autism": most pressing questions about autism \\ and mental health} (https://www.autistica.org.uk/news/5-ways-the-government-can-transform-mental-healthin-autism):

1. What mental health interventions are effective in helping autistic people with learning disabilities?

2. What clinical indicators should health professionals look for to identify depression in autistic people?

3. What makes a peer support programme personalised and effective for managing or improving mental health in autistic people?

4. What adjustments should be made to help autistic people at risk of suicide to reach support when they are at a crisis point?

5. Are anti-depressants effective treatments for depression in autistic adults? 


\section{"10 things the NHS must do about mental health and autism": Autistica's recommendation to the Government and the NHS (https://www.autistica.org.uk/news/10-things-the-nhs-must-do-about-mental-health-and-a utism):}

1. Collaborate with autistic people and their families to understand their experiences with services.

2. Cover the mental health needs of autistic children, teenagers and adults, including older adults.

3. Explain how mental health problems can look different in autistic people compared to others.

4. Address the increased and unique risk of suicide amongst autistic people.

5. Emphasise that we should not 'just accept' the mental health problems that autistic people face.

6. Recognise that each autistic person is different. Support should be personalised to their needs.

7. Begin by identifying what has worked for autistic people specifically.

8. Ensure future research into mental health and autism is adopted into practice.

9. Get the support of NHS leaders - to ensure the pathways become reality quickly across the NHS.

10. Do more than just diagnose people with autism. The NHS should not leave autistic people experiencing mental health problems behind.

\section{Panel 3. Evolving perspectives on early interventions and related ethical considerations}


Early intervention (before school-age) for children diagnosed or suspected with autism has been the core intervention strategy since 1960s. It was assumed that it is difficult for autistic children to naturally acquire skills so learning had to be facilitated by simplified instructions, learning principles and operant methodology. The conventional approach builds on Applied Behaviour Analysis (ABA, ie, understanding how environmental variables affect human behaviour) to build developmental (eg, language, motor imitation), cognitive (eg, sorting) and daily living skills (eg, getting dressed). A highly structured approach (eg, overreliance on discrete trial training, DTT, to train a specific sets of behaviour) has subsequently been recognized as having potential risks of producing stereotyped learned behaviour, lack of spontaneity, and poor generalisation of skills. Early intervention thereafter evolved to many variants, under the umbrella term of Early Intensive Behavioural Intervention (EIBI). They all share core features of ABA such as early (toddler/pre-schooler age), intensive (20-40 hours/week), long-term (1-4 years), use of DTT, one-on-one delivery of teaching by an adult therapist, comprehensive targets of skills, with some modification shifting away from overly structured approaches, eg, individualized goal-setting guided by typical developmental sequences (ie, developmentally appropriate practice), multiple behaviour analytic procedures for widening adaptive repertoires, and parent involvement as co-therapists (Reichow et al., 2018, Virues-Ortega, 2010).

The intervention models have further evolved away from the structured (traditional ABA/EIBI) towards more naturalistic approaches (Prizant and Wetherby, 1998). Such Naturalistic Developmental Behavioural Intervention (NDBI) approaches (Schreibman et al., 2015) include models such as Incidental Teaching (IT), Pivotal Response Training (PRT), Early Start Denver Model (ESDM), Enhanced Milieu Teaching (EMT), Reciprocal Imitation Training (RIT), Joint Attention Symbolic Play Engagement and Regulation (JASPER), Social Communication/Emotion Regulation/Transactional Support (SCERTS), and Social ABCs. NDBI emphasizes children's initiative and spontaneity and designs the learning to be actively engaging their attention and connecting new experiences with their existing abilities within developmental sequences. The learning targets cover the main developmental domains (ie, cognition, language, social, play, motor) with emphasis on integration across domains from the beginning and in everyday 
life (ie, skills are not taught in isolation), and on key precursors (eg, joint attention and imitation). The learning contexts are highlighted by emotionally meaningful social interactions and engagement (eg, establishing adult-child engagement activities that transform into motivating play or daily life routines); instructional strategies are development-enhancing and utilize various behavioural strategies in joint activities, and are characterized by motivating activities with highly predictable and salient rewards, designed to be integrative across domains to expand the complexity of children's abilities in ecologically valid contexts. Common features of evidence-based NDBI include manualized practice with fidelity-of-implementation criteria; individualized intervention goals; ongoing measurement of progress; child-initiated teaching episodes; environmental arrangement to facilitate the child's initiative; antecedent-response-consequence contingency; natural reinforcement to enhance motivation of the child; prompting/scaffolding; modelling; balanced turns within play routines (ie, turn-taking or shared control); adult imitation of the child's language, play, or body movements (ie, contingent imitation or mirroring); and broadening the attentional focus of the child (Schreibman et al., 2015).

Current reflection on intervention targeting at core characteristics of autism

The duality of autism framework encourages reflection on the target behaviour/symptom that requires intervention. Clinically, if a behaviour is viewed as part of the person's make-up and difference but is not interfering with the person's functioning or life (except perhaps leading to non-conformity), this may simply be the child's way of learning and stepping stone into cognitive development (eg, RRBIs related to information processing and seeking such as intense interests or hyperlexical behaviours) (Baron-Cohen et al., 2009, Mottron, 2017). A treatment that tried to reduce this behaviour may inadvertently be depriving the child of how they learn. Ethically, if we targeted behaviours to remove that are simply part of the person's make-up, by analogy it could be as if we were 'treating' individuals for having a particular skin colour. History is unfortunately replete with examples of unethical 'treatments' (e.g., for left-handedness or gay sexuality).

There have been a number of criticisms of ABA approaches by the autism 
community itself (Dawson, 2004), which sees conventional ABA as attempting to shape children's surface behaviours to resemble a neurotypical child and not allowing autistic $\begin{array}{lllll}\text { children to the themselves' } & \text { (also }\end{array}$ https://www.spectrumnews.org/features/deep-dive/controversy-autisms-common-therapy/ ). It is of historical interest that conventional ABA was undeniably useful in shaping children's behaviours and inspiring families with hope that their children's autism could be treated, hence its widespread popularity at the time. This is recently challenged particularly from the neurodiversity perspective, which asserts that the idea of 'normalising' the child is not respecting that autistic children are neurologically different and should be allowed to be so. The neurodiversity view also sees the methodology of using external rewards to shape behaviour can be challenged on the grounds that children should be motivated by intrinsic rewards that are meaningful to them, not 'bribed' by rewards offered or withheld by adults. Conventional ABA is also criticised from the neurodiversity view as 'drilling' behaviours in such a specific manner that they will likely only be produced in a specific context, such that it will likely be difficult to generalise these to new contexts. A further criticism is that the sheer amount of therapist-time devoted to data collection of every discrete trial and the child's response, for the purpose of quantifying progress, is seen as not the best use of therapist time and interfering with naturalistic interaction. Finally, ABA stems from a tradition that is Skinnerian in origin, whilst other EIBI and NDBI approaches may be preferable because they incorporate developmental and cognitive science and are more 'developmentally appropriate'.

Some elements of NDBI still have links to conventional ABA principles, such as operant conditioning and use of extrinsic rewards, and it is important to monitor if they are still at risk of targeting surface behaviours. It is still an open question whether eventual gains brought by EIBI/NDBI outweigh costs in the long run, especially considering wellbeing defined by autistic individuals themselves, which has not been well captured so far. Some argue that early interventions should be based on activities that build on the interests, strengths and unique developmental pathways of the autistic child (Mottron, 2017), and where the motivations are based on intrinsic rewards (eg, curiosity and pleasure at mastery, or a strong drive to systemise) but transposed into a more social and less individualistic context (Lindsay et al., 2017). On the other hand, 
survey data show that parents generally show positive attitudes towards autism research in early years, especially appreciating the inclusion of an 'intervention component' (Fletcher-Watson et al., 2017), reflecting high needs and expectation of early interventions.

A thorough ethical analysis for early interventions requires close examination of consequences of treatment of all aspects, from the perspectives of all stakeholders, in both utilitarianism (eg, pros and cons of an intervention) and deontology frameworks (eg, individuality or normality as ultimate values). Similarly, questions have been raised by some stakeholders about the notion of pharmacological targeting of core autism characteristics, which might be seen as incompatible with respecting autistic people's right to be different and the neurodiversity framework; this objection does not apply to targeting challenges that are causing distress and dysfunction, however (Russell et al., 2018). Such voices showcase the need for greater and ongoing consultation with the autism community in designing and implementing intervention research.

Although proper ethical analyses regarding various interventions for autistic people are beyond the scope of this review, we acknowledge they are much needed especially when more empirical data are available. Ideally, merging the neurodiversity framework with an early intervention paradigm is possible and can be significant innovation (see http://dart.ed.ac.uk/intervention-neurodiversity/).

\section{Panel 4. Current evidence of other interventions}

Complementary and alternative treatments (CAT) are frequently pursued by parents of autistic children, perhaps due to the lack of definite biomedical intervention to 'alleviate' core autism characteristics and associated difficulties, and available treatment for co-occurring difficulties may be viewed as symptomatic treatment only. Clinicians providing care to families should inquire into the use of CAT and be prepared to discuss their evidence base, risk and benefits (Bent and Hendren, 2015, Volkmar et al., 2014). Overall there is still a lack of conclusive efficacy (Whitehouse, 2013). Some approaches 
show potentially promising results (eg, music therapy, massage, acupuncture, animal-assistance, exercise) (Brondino et al., 2015), but others do not (eg, gluten/casein-free diets) (Piwowarczyk et al., 2018) and some even have significant concerns of harm (eg, chelation, sex hormone-inhibiting drugs such as leuprolide) (Singer and Ravi, 2015). Among the more promising approaches, a Cochrane review found music therapy (1 week to 7 months) shows evidence (low to moderate quality) in promoting autistic children's social interaction, verbal communication, initiating behaviour, social-emotional reciprocity, social adaptation, and parent-child relationship quality, even generalizing outside the sessions, and with no reported adverse effects (Geretsegger et al., 2014). Massage therapy is supported by a limited amount of trials, with high risk of bias, in improving sensory profile, social-communication and adaptive behaviour during trial periods (Lee et al., 2011). Acupuncture is not yet supported to be beneficial for autism characteristics, although some trials show variably reduced challenging behaviour and improved communication, social interaction, cognitive or global functioning and with acceptable adverse events, with very low quality of evidence and high heterogeneity of the acupuncture methods (Cheuk et al., 2011, Lee et al., 2018). There is some preliminary evidence for animal-assisted intervention (with therapy, service or companion animals) in improving various functioning in individuals with autism, although this needs to be tested with more rigorous trials (O'Haire, 2013). Autistic individuals are more likely to have lower physical activity and more sedentary behaviour compared with non-autistic counterparts (Jones et al., 2017b). Exercise interventions for autistic individuals are varied (eg, jogging, horseback riding, martial arts, yoga, dance, swimming, weight-bearing) and tend to show benefits for motor, physical, behavioural or cognitive outcomes (Bremer et al., 2016, Dillon et al., 2016, Healy et al., 2018, Tan et al., 2016). Evidence of benefits of nutritional and dietary intervention is limited: based on small strength of evidence, omega-3 fatty acids do not reduce challenging behaviour or alter core autism characteristics (Horvath et al., 2017, Sathe et al., 2017); based on insufficient strength of evidence, although some benefits have been reported for digestive enzymes, methyl-B12, levocarnitine, and gluten/casein-free diets, results are all inconclusive and give little evidence to support the use of nutritional supplements or dietary therapies for autistic children (Sathe et al., 2017); benefits, if reported, are often related to gastrointestinal (eg, food intolerance, malabsorption) or allergy issues (eg, grain allergy) 
instead of autism characteristics per se. On the other hand, there is no evidence supporting chelation as an effective intervention for autism. Rather, it has potentially serious adverse effects (James et al., 2015). Similarly, there is no of evidence supporting the benefits of hyperbaric oxygen therapy, and again this also has potentially serious adverse effects (Xiong et al., 2016). No evidence of benefits are found for secretin (Williams et al., 2012). 
Tables

Table 1. Summary from the latest Cochrane Database of Systematic Reviews on intervention/treatment/support for individuals with autism

\begin{tabular}{|c|c|c|c|c|c|}
\hline Intervention & $\begin{array}{l}\text { Summary of } \\
\text { intervention }\end{array}$ & Population & Evidence of benefit & $\begin{array}{l}\text { Evidence of } \\
\text { safety }\end{array}$ & $\begin{array}{l}\text { Quality of } \\
\text { evidence } \\
\text { (GRADE) }\end{array}$ \\
\hline \multicolumn{6}{|l|}{$\begin{array}{l}\text { Maximizing } \\
\text { potential }\end{array}$} \\
\hline $\begin{array}{l}\text { Early intensive } \\
\text { behavioural } \\
\text { intervention (EIBI) } \\
\text { (2018) (Reichow et } \\
\text { al., 2018); updated } \\
\text { from an earlier } \\
\text { review in } 2012 \\
\text { (Reichow et al., } \\
2012 \mathrm{a})\end{array}$ & $\begin{array}{l}\text { Based on applied } \\
\text { behavioural } \\
\text { analysis (ABA) } \\
\text { principles } \\
\text { including discrete } \\
\text { trial training, } \\
\text { one-on-one adult } \\
\text { therapist-to-child, } \\
\text { implementation in } \\
\text { either home or }\end{array}$ & $\begin{array}{l}\text { Children (less than } \\
6 \text { years-old at onset } \\
\text { of treatment) with } \\
\text { autism based on } \\
\text { DSM-IV, DSM-5 or } \\
\text { ICD-10 criteria for } \\
\text { Pervasive } \\
\text { Developmental } \\
\text { Disorder or Autism } \\
\text { Spectrum Disorder, }\end{array}$ & $\begin{array}{l}\text { One RCT and } 4 \text { CCTs with } \\
219 \text { participants, on EIBI } \\
\text { effectiveness. Positive } \\
\text { effects in favour of EIBI for } \\
\text { adaptive behaviour but not } \\
\text { autism symptom severity } \\
\text { (primary outcomes); } \\
\text { Positive effects in favour of } \\
\text { EIBI for intelligence } \\
\text { quotient, expressive and }\end{array}$ & $\begin{array}{l}\text { No adverse } \\
\text { effects reported }\end{array}$ & Low \\
\hline
\end{tabular}




\begin{tabular}{|c|c|c|c|c|c|}
\hline & $\begin{array}{l}\text { school settings, } \\
\text { delivered for 1-4 } \\
\text { years, } 20-40 \\
\text { hours/week }\end{array}$ & $\begin{array}{l}\text { no exclusion based } \\
\text { on IQ or } \\
\text { comorbidities }\end{array}$ & $\begin{array}{l}\text { receptive language skills, } \\
\text { but not problem behaviour } \\
\text { (secondary outcomes). }\end{array}$ & & \\
\hline $\begin{array}{l}\text { Parent-mediated } \\
\text { early intervention } \\
\text { (2013) (Oono et al., } \\
\text { 2013) }\end{array}$ & $\begin{array}{l}\text { Home-based } \\
\text { and/or } \\
\text { clinic-based, } \\
\text { delivered on a } \\
\text { one-on-one basis } \\
\text { or to groups of } \\
\text { parents, or } \\
\text { self-training from a } \\
\text { manual and } \\
\text { videotapes, lasting } \\
\text { from } 1 \text { week to } 2 \\
\text { years. }\end{array}$ & $\begin{array}{l}\text { Children ( } 17 \\
\text { months to } 6 \text { years) } \\
\text { with autism based } \\
\text { on DSM-IV or } \\
\text { ICD-10 criteria for } \\
\text { Pervasive } \\
\text { Developmental } \\
\text { Disorder }\end{array}$ & $\begin{array}{l}17 \text { RCTs, } 919 \text { participants, } \\
\text { on intervention } \\
\text { effectiveness; largest } \\
\text { meta-analysis combined } \\
\text { data from } 316 \text { participants in } \\
6 \text { studies, smallest combined } \\
\text { data from } 55 \text { participants in } \\
\text { two studies. No benefit for } \\
\text { most of the primary } \\
\text { outcomes; Positive effects } \\
\text { found for shared attention } \\
\text { and parent synchrony, } \\
\text { improvements in child } \\
\text { vocabulary comprehension, } \\
\text { and reduction in the severity } \\
\text { of autism symptoms. }\end{array}$ & $\begin{array}{l}\text { No adverse } \\
\text { effects reported }\end{array}$ & Low \\
\hline
\end{tabular}




\begin{tabular}{|c|c|c|c|c|c|}
\hline $\begin{array}{l}\text { Social skills groups } \\
\text { (2012) (Reichow et } \\
\text { al., 2012b) }\end{array}$ & $\begin{array}{l}5-20 \text { weeks or } \\
12-125 \text { sessions } \\
\text { (each lasting } 60-90 \\
\text { minutes) }\end{array}$ & $\begin{array}{l}\text { Individuals (6-21 } \\
\text { years) with autism } \\
\text { based on DSM-IV } \\
\text { or ICD-10 criteria } \\
\text { for Pervasive } \\
\text { Developmental } \\
\text { Disorder }\end{array}$ & $\begin{array}{l}5 \text { RCTs, } 196 \text { participants, on } \\
\text { social skills group } \\
\text { effectiveness. Benefits for } \\
\text { social competence, } \\
\text { friendship quality and } \\
\text { loneliness; no benefits for } \\
\text { emotional recognition, } \\
\text { social communication } \\
\text { relating to understanding } \\
\text { idioms, or child or parental } \\
\text { depression. }\end{array}$ & $\begin{array}{l}\text { No adverse } \\
\text { effects reported }\end{array}$ & Low \\
\hline $\begin{array}{l}\text { Theory of Mind } \\
(\text { ToM) interventions } \\
(2014) \\
\text { (Fletcher-Watson et } \\
\text { al., 2014) }\end{array}$ & $\begin{array}{l}\text { ToM cognitive } \\
\text { interventions } \\
\text { delivered via } \\
\text { computer } \\
\text { programs, } \\
\text { one-on-one } \\
\text { therapist led } \\
\text { interventions, or } \\
\text { teacher training in } \\
\text { classrooms, for } 2\end{array}$ & $\begin{array}{l}\text { Children, } \\
\text { adolescents and } \\
\text { adults with autism } \\
\text { based on DSM-IV } \\
\text { or ICD-10 criteria } \\
\text { for Pervasive } \\
\text { Developmental } \\
\text { Disorder; majority } \\
\text { of studies included } \\
\text { preschool and }\end{array}$ & $\begin{array}{l}22 \text { RCTs, } 695 \text { participants, } \\
\text { on intervention } \\
\text { effectiveness; only } 3 \text { small } \\
\text { meta-analysis possible due } \\
\text { to outcome and intervention } \\
\text { heterogeneity. Some } \\
\text { evidence that ToM or a } \\
\text { precursor skill (ie, emotion } \\
\text { recognition, joint attention) } \\
\text { can be taught, but little }\end{array}$ & $\begin{array}{l}\text { No adverse } \\
\text { effects reported }\end{array}$ & $\begin{array}{l}\text { Low to very } \\
\text { low }\end{array}$ \\
\hline
\end{tabular}




\begin{tabular}{|c|c|c|c|c|c|}
\hline & weeks to 6 months & $\begin{array}{l}\text { primary school aged } \\
\text { children }\end{array}$ & $\begin{array}{l}\text { evidence of skill } \\
\text { maintenance, generalization } \\
\text { to other settings or } \\
\text { developmental effects on } \\
\text { related skills. }\end{array}$ & & \\
\hline \multicolumn{6}{|l|}{ Minimizing barrier } \\
\hline $\begin{array}{l}\text { Risperidone (2007) } \\
\text { (Jesner et al., 2007) }\end{array}$ & $\begin{array}{l}\text { Risperidone } \\
\text { maximum } 2 \cdot 5-10 \\
\mathrm{mg} / \text { day (or } 0 \cdot 06 \\
\mathrm{mg} / \mathrm{kg} / \text { day), for } 8 \\
\text { to } 12 \text { weeks }\end{array}$ & $\begin{array}{l}\text { Individuals (5-17 } \\
\text { years) with autism } \\
\text { based on DSM-IV } \\
\text { or ICD-10 criteria } \\
\text { for Pervasive } \\
\text { Developmental } \\
\text { Disorder }\end{array}$ & $\begin{array}{l}3 \text { RCTs, } 211 \text { participants, on } \\
\text { risperidone efficacy; } \\
\text { meta-analysis possible for } 3 \\
\text { outcomes (ie, ABC, CGI and } \\
\text { weight gain). Benefits found } \\
\text { for irritability, repetition and } \\
\text { social withdrawal. }\end{array}$ & $\begin{array}{l}\text { Higher risk of } \\
\text { adverse effects, } \\
\text { especially } \\
\text { weight gain }\end{array}$ & Not assessed \\
\hline $\begin{array}{l}\text { Aripiprazole (2016) } \\
\text { (Hirsch and } \\
\text { Pringsheim, 2016); } \\
\text { updated from an } \\
\text { earlier review in } \\
2012 \text { (Ching and } \\
\text { Pringsheim, 2012) }\end{array}$ & $\begin{array}{l}\text { Aripiprazole } 2-15 \\
\mathrm{mg} / \text { day, for } 8 \text { to } 16 \\
\text { weeks }\end{array}$ & $\begin{array}{l}\text { Individuals (6-17 } \\
\text { years) with autism } \\
\text { based on DSM-IV, } \\
\text { ICD-10, or DSM-5 } \\
\text { criteria for } \\
\text { Pervasive } \\
\text { Developmental } \\
\text { Disorder or Autism }\end{array}$ & $\begin{array}{l}3 \text { RCTs, } 401 \text { participants, on } \\
\text { aripiprazole efficacy; } \\
\text { several meta-analyses } \\
\text { possible. Short term studies } \\
\text { found improvements in } \\
\text { irritability, hyperactivity and } \\
\text { stereotypy. }\end{array}$ & $\begin{array}{l}\text { Higher risk of } \\
\text { adverse effects } \\
\text { of weight gain, } \\
\text { sedation, and } \\
\text { tremor }\end{array}$ & Moderate \\
\hline
\end{tabular}




\begin{tabular}{|c|c|c|c|c|c|}
\hline & & $\begin{array}{l}\text { Spectrum Disorder, } \\
\text { corroborated by } \\
\text { ADI-R }\end{array}$ & & & \\
\hline $\begin{array}{l}\text { Methylphenidate } \\
\text { (2017) (Sturman et } \\
\text { al., 2017) }\end{array}$ & $\begin{array}{l}\text { Immediate or } \\
\text { extended release } \\
\text { methylphenidate, } \\
\text { at various dosing } \\
\text { schedules ( } 2 \text { or } 3 \\
\text { different doses per } \\
\text { day) }\end{array}$ & $\begin{array}{l}\text { Children (5-13 } \\
\text { years) with autism } \\
\text { based on DSM-III, } \\
\text { DSM-IV or ICD-10 } \\
\text { criteria for } \\
\text { Pervasive } \\
\text { Developmental } \\
\text { Disorder and with } \\
\text { ADHD-like } \\
\text { symptoms }\end{array}$ & $\begin{array}{l}4 \text { cross-over RCTs, } 113 \\
\text { participants ( } 83 \% \text { boys) on } \\
\text { methylphenidate } \\
\text { effectiveness. In those who } \\
\text { were able to tolerate, } \\
\text { short-term, high-dose } \\
\text { methylphenidate } \\
(0 \cdot 43 \mathrm{mg} / \mathrm{kg} / \text { dose to } \\
0 \cdot 60 \mathrm{mg} / \mathrm{kg} / \text { dose) has } \\
\text { significant and clinically } \\
\text { relevant benefits on } \\
\text { hyperactivity; significant but } \\
\text { not clinically relevant } \\
\text { benefit on teacher-rated } \\
\text { inattention; inadequate data } \\
\text { to conduct a meta-analysis } \\
\text { on impulsivity. No evidence } \\
\text { methylphenidate benefits or }\end{array}$ & $\begin{array}{l}\text { No serious } \\
\text { adverse effects } \\
\text { reported; adverse } \\
\text { effect more } \\
\text { likely with } \\
\text { treatment was } \\
\text { reduced appetite } \\
\text { (parent-report); } \\
\text { studies excluded } \\
\text { children } \\
\text { intolerant of } \\
\text { methylphenidate } \\
\text { so risk may be } \\
\text { higher than } \\
\text { reported }\end{array}$ & $\begin{array}{l}\text { Low (and very } \\
\text { low for adverse } \\
\text { effects) }\end{array}$ \\
\hline
\end{tabular}




\begin{tabular}{|c|c|c|c|c|c|}
\hline & & & $\begin{array}{l}\text { worsens core features of } \\
\text { autism. }\end{array}$ & & \\
\hline $\begin{array}{l}\text { Selective serotonin } \\
\text { reuptake inhibitors } \\
\text { (SSRIs) (2013) } \\
\text { (Williams et al., } \\
2013 \text { ) }\end{array}$ & $\begin{array}{l}\text { Four SSRIs: } \\
\text { fluoxetine ( } 3 \text { trials, } \\
\text { 10-80 mg/day for } \\
\text { 8-12 weeks), } \\
\text { fluvoxamine ( } 2 \\
\text { trials, up to } 300 \\
\text { mg/day for } 9-12 \\
\text { weeks), } \\
\text { fenfluramine ( } 2 \\
\text { trials, } 1 \cdot 5 \\
\text { mg/kg/day for } 3 \\
\text { months), and } \\
\text { citalopram ( } 2 \\
\text { trials, up to } 30 \\
\text { mg/day) }\end{array}$ & $\begin{array}{l}\text { Adults ( } 4 \text { studies) } \\
\text { and children }<18 \\
\text { years ( } 5 \text { studies) } \\
\text { with autism based } \\
\text { on DSM-IV or } \\
\text { ICD-10 criteria for } \\
\text { Pervasive } \\
\text { Developmental } \\
\text { Disorder }\end{array}$ & $\begin{array}{l}9 \text { RCTs, } 320 \text { participants, on } \\
\text { SSRIs effectiveness; } \\
\text { meta-analysis possible for } \\
\text { proportion improvement } \\
\text { outcome measure. No } \\
\text { evidence of positive effects } \\
\text { for SSRIs in children, } \\
\text { limited evidence for } \\
\text { effectiveness in adults } \\
\text { (improved CGI, reduced } \\
\text { obsessive-compulsive } \\
\text { behaviour, aggression, } \\
\text { anxiety). }\end{array}$ & $\begin{array}{l}\text { Emerging } \\
\text { evidence of } \\
\text { harm in children }\end{array}$ & $\begin{array}{l}\text { Not assessed } \\
\text { (but note: small } \\
\text { studies, unclear } \\
\text { risk of bias) }\end{array}$ \\
\hline $\begin{array}{l}\text { Tricyclic } \\
\text { antidepressants } \\
(\mathrm{TCA})(2012)\end{array}$ & $\begin{array}{l}\text { Clomipramine ( } 2 \\
\text { studies) or } \\
\text { tianeptine ( } 1 \text { study) }\end{array}$ & $\begin{array}{l}\text { Children }(<18 \\
\text { years) and young } \\
\text { adults (18-35 years) }\end{array}$ & $\begin{array}{l}3 \text { RCTs, } 67 \text { participants on } \\
\text { TCA effectiveness; no } \\
\text { meta-analyses possible. }\end{array}$ & $\begin{array}{l}\text { Tianeptine } \\
\text { associated with } \\
\text { significant }\end{array}$ & $\begin{array}{l}\text { Not assessed } \\
\text { (but note: } \\
\text { limited and }\end{array}$ \\
\hline
\end{tabular}




\begin{tabular}{|c|c|c|c|c|c|}
\hline $\begin{array}{l}\text { (Hurwitz et al., } \\
\text { 2012) }\end{array}$ & $\begin{array}{l}\text { for } 5-7 \text { weeks (no } \\
\text { specified doses) }\end{array}$ & $\begin{array}{l}\text { with autism based } \\
\text { on DSM-III-R, } \\
\text { DSM-IV or ICD-10 } \\
\text { criteria for Autistic } \\
\text { Disorder or } \\
\text { Childhood Autism }\end{array}$ & $\begin{array}{l}\text { Inconsistent impacts on core } \\
\text { autism features. A tianeptine } \\
\text { trial reporting short term } \\
\text { effects for reducing } \\
\text { irritability, hyperactivity, } \\
\text { inadequate eye contact and } \\
\text { inappropriate speech on } \\
\text { parent reports but not } \\
\text { clinician rating; } \\
\text { contradictory effects of } \\
\text { clomipramine for autism } \\
\text { characteristics, irritability } \\
\text { and obsessive-compulsive } \\
\text { symptoms. }\end{array}$ & $\begin{array}{l}\text { adverse effects, } \\
\text { including } \\
\text { drowsiness and } \\
\text { reduced activity } \\
\text { levels; adverse } \\
\text { effects also } \\
\text { reported with the } \\
\text { use of } \\
\text { clomipramine } \\
\text { (higher dropout } \\
\text { rate) }\end{array}$ & $\begin{array}{l}\text { conflicted } \\
\text { evidence of } \\
\text { effect and } \\
\text { adverse effect } \\
\text { profile) }\end{array}$ \\
\hline $\begin{array}{l}\text { Intravenous secretin } \\
(2012) \text { (Williams et } \\
\text { al., 2012); updated } \\
\text { from an earlier } \\
\text { review in } 2005 \\
\text { (Williams et al., } \\
\text { 2005) }\end{array}$ & $\begin{array}{l}\text { Porcine or } \\
\text { synthetic human } \\
\text { secretin in single } \\
\text { or repeated doses, } \\
\text { with various } \\
\text { dosing schedule }\end{array}$ & $\begin{array}{l}\text { Children }(<18 \\
\text { years) with autism } \\
\text { based on DSM-IV } \\
\text { or ICD-10 criteria } \\
\text { for Pervasive } \\
\text { Developmental } \\
\text { Disorder }\end{array}$ & $\begin{array}{l}16 \text { RCTs, } 911 \text { participants } \\
\text { on secretin efficacy; } \\
\text { meta-analysis of data not } \\
\text { possible due to outcome } \\
\text { heterogeneity. No evidence } \\
\text { of improvements of core } \\
\text { features of autism. }\end{array}$ & $\begin{array}{l}\text { No serious } \\
\text { adverse effects } \\
\text { reported in any } \\
\text { study, but some } \\
\text { minor adverse } \\
\text { effects }\end{array}$ & Not assessed \\
\hline
\end{tabular}




\begin{tabular}{|c|c|c|c|c|c|}
\hline $\begin{array}{l}\text { Enhancing } \\
\text { person-environment } \\
\text { fit }\end{array}$ & & & & & \\
\hline $\begin{array}{l}\text { Family therapy } \\
\text { (2017) (Spain et al., } \\
\text { 2017) }\end{array}$ & $\begin{array}{l}\text { Family (systemic) } \\
\text { therapy to enhance } \\
\text { communication, } \\
\text { relationships and } \\
\text { coping for autistic } \\
\text { individuals and } \\
\text { their wider family } \\
\text { network }\end{array}$ & Unknown & $\begin{array}{l}\text { No trials met the inclusion } \\
\text { criteria }\end{array}$ & Unknown & Unknown \\
\hline $\begin{array}{l}\text { Complementary } \\
\text { and alternative } \\
\text { treatment }\end{array}$ & & & & & \\
\hline $\begin{array}{l}\text { Music therapy } \\
(2014) \text { (Geretsegger } \\
\text { et al., 2014) }\end{array}$ & $\begin{array}{l}\text { Music therapy } \\
\text { delivered by a } \\
\text { professional music } \\
\text { therapist for one } \\
\text { week to } 7 \text { months }\end{array}$ & $\begin{array}{l}\text { Children (2-9 years) } \\
\text { with autism based } \\
\text { on DSM-IV or } \\
\text { ICD-10 criteria for } \\
\text { Pervasive } \\
\text { Developmental }\end{array}$ & $\begin{array}{l}10 \text { RCTs or CCTs, } 165 \\
\text { participants on music } \\
\text { therapy effectiveness. } \\
\text { Effects in favour of music } \\
\text { therapy for social interaction } \\
\text { (within and outside therapy }\end{array}$ & $\begin{array}{l}\text { No adverse } \\
\text { effects reported }\end{array}$ & $\begin{array}{l}\text { Low to } \\
\text { moderate }\end{array}$ \\
\hline
\end{tabular}




\begin{tabular}{|c|c|c|c|c|c|}
\hline & & Disorder & $\begin{array}{l}\text { contexts), verbal } \\
\text { communication skills } \\
\text { (within and outside therapy } \\
\text { contexts), non-verbal } \\
\text { communication skills, } \\
\text { initiating behaviour, and } \\
\text { social-emotional reciprocity } \\
\text { (all within therapy context); } \\
\text { also for social adaption, joy, } \\
\text { and quality of parent-child } \\
\text { relationships. }\end{array}$ & & \\
\hline $\begin{array}{l}\text { Omega-3 fatty acids } \\
\text { supplementation } \\
\text { (2011) (James et al., } \\
\text { 2011) }\end{array}$ & $\begin{array}{l}\text { As a capsule or a } \\
\text { pudding, with } \\
\text { doses ranging from } \\
1 \cdot 3 \mathrm{~g} / \text { day }(0 \cdot 7 \mathrm{~g} \text { of } \\
\text { eicosapentaenoic } \\
\text { acid and } 0 \cdot 46 \mathrm{~g} \text { of } \\
\text { docosahexaenoic } \\
\text { acid }) \text { to } 1.5 \mathrm{~g} / \text { day } \\
(0.84 \mathrm{~g} \text { of } \\
\text { eicosapentaenoic }\end{array}$ & $\begin{array}{l}\text { Children (5-17 } \\
\text { years) with autism } \\
\text { based on DSM-IV } \\
\text { or ICD-10 criteria } \\
\text { for Pervasive } \\
\text { Developmental } \\
\text { Disorder }\end{array}$ & $\begin{array}{l}2 \text { RCTs, } 37 \text { participants on } \\
\text { treatment efficacy. No } \\
\text { benefits for social } \\
\text { interaction, communication, } \\
\text { stereotypy or hyperactivity. }\end{array}$ & $\begin{array}{l}\text { No reported } \\
\text { adverse effects }\end{array}$ & Low \\
\hline
\end{tabular}




\begin{tabular}{|c|c|c|c|c|c|}
\hline & $\begin{array}{l}\text { acid and } 0 \cdot 7 \mathrm{~g} \text { of } \\
\text { docosahexaenoic } \\
\text { acid), for } 6-12 \\
\text { weeks. }\end{array}$ & & & & \\
\hline $\begin{array}{l}\text { Gluten- and } \\
\text { casein-free diets } \\
(2008) \text { (Millward et } \\
\text { al., 2008) }\end{array}$ & $\begin{array}{l}\text { Gluten- and casein- } \\
\text { free diets for } 12 \\
\text { weeks or } 12 \\
\text { months }\end{array}$ & $\begin{array}{l}\text { Children (2-16 } \\
\text { years) with autism } \\
\text { based on DSM-IV } \\
\text { or ICD-10 criteria } \\
\text { for Pervasive } \\
\text { Developmental } \\
\text { Disorder }\end{array}$ & $\begin{array}{l}2 \text { RCTs, } 35 \text { participants on } \\
\text { diet-modification } \\
\text { effectiveness; no } \\
\text { meta-analysis possible. } \\
\text { Benefits for only } 3 \\
\text { outcomes, ie, reducing } \\
\text { overall autistic traits, social } \\
\text { isolation, and increasing } \\
\text { overall ability to } \\
\text { communicate and interact. }\end{array}$ & $\begin{array}{l}\text { No adverse } \\
\text { effects reported }\end{array}$ & Very Low \\
\hline $\begin{array}{l}\text { Combined vitamin } \\
\text { B6-magnesium } \\
(2005) \text { (Nye and } \\
\text { Brice, 2005) }\end{array}$ & $\begin{array}{l}\text { Vitamin B6 up to } \\
30 \mathrm{mg} / \mathrm{kg} / \text { day } \\
\text { (maximum } 1 \\
\mathrm{~g} / \text { day) and } \\
\text { magnesium up to } \\
10 \mathrm{mg} / \mathrm{kg} / \text { day }\end{array}$ & $\begin{array}{l}\text { Children }(<18 \\
\text { years) with autism } \\
\text { based on DSM-IV } \\
\text { or ICD-10 criteria } \\
\text { for Pervasive } \\
\text { Developmental }\end{array}$ & $\begin{array}{l}3 \text { RCTs, } 33 \text { participants on } \\
\text { B6-magnesium efficacy; no } \\
\text { meta-analysis possible. No } \\
\text { benefits for social } \\
\text { interaction, communication, } \\
\text { compulsivity, impulsivity or }\end{array}$ & $\begin{array}{l}\text { No adverse } \\
\text { effects reported }\end{array}$ & $\begin{array}{l}\text { Not assessed } \\
\text { (but note: small } \\
\text { number of } \\
\text { studies, poor } \\
\text { methodological } \\
\text { quality, small }\end{array}$ \\
\hline
\end{tabular}




\begin{tabular}{|c|c|c|c|c|c|}
\hline & $\begin{array}{l}\text { (maximum } 350 \\
\mathrm{mg} / \text { day), for } 4-20 \\
\text { weeks }\end{array}$ & Disorder & $\begin{array}{l}\text { hyperactivity; one small trial } \\
(\mathrm{n}=8) \text { reporting improved IQ } \\
\text { in a subgroup exhibiting } \\
\text { clinical features similar to } \\
\text { pyroxidine-dependent } \\
\text { epilepsy. }\end{array}$ & & sample size) \\
\hline $\begin{array}{l}\text { Acupuncture (2011) } \\
\text { (Cheuk et al., 2011) }\end{array}$ & $\begin{array}{l}\text { Needle } \\
\text { acupuncture or } \\
\text { acupressure } \\
\text { without needle } \\
\text { puncture, for } 4 \\
\text { weeks to } 9 \text { months }\end{array}$ & $\begin{array}{l}\text { Children (3-18 } \\
\text { years) with autism } \\
\text { based on DSM-IV } \\
\text { or ICD-10 criteria } \\
\text { for Pervasive } \\
\text { Developmental } \\
\text { Disorder }\end{array}$ & $\begin{array}{l}10 \text { RCTs and quasi-RCTs, } \\
390 \text { participants on } \\
\text { effectiveness; some } \\
\text { meta-analyses possible. } \\
\text { Inconsistent benefits for } \\
\text { core autism characteristics } \\
\text { and associated features. }\end{array}$ & $\begin{array}{l}\text { Adverse effects } \\
\text { included } \\
\text { bleeding, crying } \\
\text { due to fear or } \\
\text { pain, irritability, } \\
\text { sleep disturbance } \\
\text { or hyperactivity }\end{array}$ & Very low \\
\hline $\begin{array}{l}\text { Auditory integration } \\
\text { training and other } \\
\text { sound therapies } \\
\text { (2011) (Sinha et al., } \\
2011 \text { ) }\end{array}$ & $\begin{array}{l}\text { Auditory } \\
\text { integration therapy } \\
\text { ( } 6 \text { trials) or } \\
\text { Tomatis therapy ( } 1 \\
\text { trial) for } 10 \text { days to } \\
14 \text { months }\end{array}$ & $\begin{array}{l}\text { Children and adults } \\
\text { (3-39 years) with } \\
\text { autism based on } \\
\text { DSM-IV or ICD-10 } \\
\text { criteria for } \\
\text { Pervasive } \\
\text { Developmental } \\
\text { Disorder }\end{array}$ & $\begin{array}{l}7 \text { RCTs, } 182 \text { participants on } \\
\text { intervention effectiveness; } \\
\text { no meta-analysis possible. } \\
\text { No evidence suggesting } \\
\text { benefits. }\end{array}$ & $\begin{array}{l}\text { No adverse } \\
\text { effects reported }\end{array}$ & Very Low \\
\hline
\end{tabular}




\begin{tabular}{|c|c|c|c|c|c|}
\hline $\begin{array}{l}\text { Chelation (2015) } \\
\text { (James et al., 2015) }\end{array}$ & $\begin{array}{l}\text { Glutathione lotion } \\
\text { followed by up to } 6 \\
\text { cycles of oral } \\
\text { dimercaptosuccinic } \\
\text { acid (DMSA), for } \\
4 \text { months }\end{array}$ & $\begin{array}{l}\text { Children (3-8 years) } \\
\text { with autism based } \\
\text { on clinical } \\
\text { diagnosis }\end{array}$ & $\begin{array}{l}1 \mathrm{RCT}, 77 \text { participants to } \\
\text { assess chelation } \\
\text { effectiveness. No evidence } \\
\text { suggesting benefits in any } \\
\text { domain. }\end{array}$ & $\begin{array}{l}\text { Some adverse } \\
\text { effects reported; } \\
\text { prior reports of } \\
\text { hypocalcaemia, } \\
\text { renal impairment } \\
\text { and reported } \\
\text { death; risks } \\
\text { currently } \\
\text { outweigh proven } \\
\text { benefits }\end{array}$ & Very Low \\
\hline $\begin{array}{l}\text { Hyperbaric oxygen } \\
\text { therapy }(2016) \\
\text { (Xiong et al., 2016) }\end{array}$ & $\begin{array}{l}\text { Hyperbaric oxygen } \\
\text { therapy (pressure } \\
\text { of } 1 \cdot 5 \text { ATA with } \\
100 \% \text { oxygen), } 20 \\
\text { one-hour sessions } \\
\text { held on weekdays } \\
\text { over } 10 \text { weeks }\end{array}$ & $\begin{array}{l}\text { Children (3-9 years) } \\
\text { with autism based } \\
\text { on DSM-IV criteria } \\
\text { for Pervasive } \\
\text { Developmental } \\
\text { Disorder }\end{array}$ & $\begin{array}{l}1 \mathrm{RCT}, 60 \text { participants to } \\
\text { assess intervention } \\
\text { effectiveness. No evidence } \\
\text { suggesting benefits in any } \\
\text { domain. }\end{array}$ & $\begin{array}{l}\text { Adverse effects } \\
\text { reported and } \\
\text { more likely in } \\
\text { the treatment } \\
\text { group, eg, } \\
\text { minor-grade ear } \\
\text { barotrauma }\end{array}$ & Low \\
\hline
\end{tabular}

\section{Abbreviations:}

GRADE - Grading of Recommendations, Assessment, Development and Evaluations

EIBI - Early Intensive Behavioural Interventions 
RCTs - Randomized controlled trials

CCTs - Clinical Controlled Trials

SSRIs - Selective serotonin reuptake inhibitors

TCA - tricyclic antidepressants

ToM - Theory of Mind 
References

Aman, M. G., Findling, R. L., Hardan, A. Y., Hendren, R. L., Melmed, R. D., Kehinde-Nelson, O., Hsu, H. A., Trugman, J. M., Palmer, R. H., Graham, S. M., Gage, A. T., Perhach, J. L. \& Katz, E. (2017). Safety and Efficacy of Memantine in Children with Autism: Randomized, Placebo-Controlled Study and Open-Label Extension. J Child Adolesc Psychopharmacol 27, 403-412.

Ameis, S. H., Corbett-Dick, P., Cole, L. \& Correll, C. U. (2013). Decision making and antipsychotic medication treatment for youth with autism spectrum disorders: applying guidelines in the real world. J Clin Psychiatry 74, 1022-4.

Ameis, S. H., Kassee, C., Corbett-Dick, P., Cole, L., Dadhwal, S., Lai, M. C., Veenstra-VanderWeele, J. \& Correll, C. U. (2018). Systematic review and guide to management of core and psychiatric symptoms in youth with autism. Acta Psychiatr Scand.

American Psychiatric Association (2013). Diagnostic and Statistical Manual of Mental Disorders, 5th edition (DSM-5). American Psychiatric Publishing, Inc.: Washington, DC. Anagnostou, E. (2018). Clinical trials in autism spectrum disorder: evidence, challenges and future directions. Curr Opin Neurol 31, 119-125.

Anagnostou, E., Aman, M. G., Handen, B. L., Sanders, K. B., Shui, A., Hollway, J. A., Brian, J., Arnold, L. E., Capano, L., Hellings, J. A., Butter, E., Mankad, D., Tumuluru, R., Kettel, J., Newsom, C. R., Hadjiyannakis, S., Peleg, N., Odrobina, D., McAuliffe-Bellin, S., Zakroysky, P., Marler, S., Wagner, A., Wong, T., Macklin, E. A. \& Veenstra-VanderWeele, J. (2016). Metformin for Treatment of Overweight Induced by Atypical Antipsychotic Medication in Young People With Autism Spectrum Disorder: A Randomized Clinical Trial. JAMA Psychiatry 73, 928-37.

Anagnostou, E., Soorya, L., Brian, J., Dupuis, A., Mankad, D., Smile, S. \& Jacob, S. (2014a). Intranasal oxytocin in the treatment of autism spectrum disorders: a review of literature and early safety and efficacy data in youth. Brain Res 1580, 188-98.

Anagnostou, E., Soorya, L., Chaplin, W., Bartz, J., Halpern, D., Wasserman, S., Wang, A.

T., Pepa, L., Tanel, N., Kushki, A. \& Hollander, E. (2012). Intranasal oxytocin versus placebo in the treatment of adults with autism spectrum disorders: a randomized 
controlled trial. Mol Autism 3, 16.

Anagnostou, E., Zwaigenbaum, L., Szatmari, P., Fombonne, E., Fernandez, B. A., Woodbury-Smith, M., Brian, J., Bryson, S., Smith, I. M., Drmic, I., Buchanan, J. A., Roberts, W. \& Scherer, S. W. (2014b). Autism spectrum disorder: advances in evidence-based practice. CMAJ 186, 509-19.

Asperger, H. (1944). Die "autistichen psychopathen" im kindersalter [Autistic psychopathy in childhood]. Archive fur Psychiatrie und Nervenkrankheiten 117, 76-136. Asperger, H. (1944/1991). 'Autistic psychopathy' in childhood. In Autism and Asperger syndrome (ed. U. Frith), pp. 37-92. Cambridge University Press: Cambridge, UK. Aspiranti, K. B., Larwin, K. H. \& Schade, B. P. (2018). iPads/tablets and students with autism: a meta-analysis of academic effects. Assist Technol.

Baron-Cohen, S. (2008). Autism, hypersystemizing, and truth. Q J Exp Psychol (Colchester) 61, 64-75.

Baron-Cohen, S., Ashwin, E., Ashwin, C., Tavassoli, T. \& Chakrabarti, B. (2009). Talent in autism: hyper-systemizing, hyper-attention to detail and sensory hypersensitivity. Philos Trans R Soc Lond B Biol Sci 364, 1377-83.

Bassett, A. S. (2011). Parental origin, DNA structure, and the schizophrenia spectrum. Am J Psychiatry 168, 350-3.

Bauman, M. L. (2010). Medical comorbidities in autism: challenges to diagnosis and treatment. Neurotherapeutics 7, 320-7.

Baxter, A. J., Brugha, T. S., Erskine, H. E., Scheurer, R. W., Vos, T. \& Scott, J. G. (2015). The epidemiology and global burden of autism spectrum disorders. Psychol Med 45, 601-13.

Bent, S. \& Hendren, R. L. (2015). Complementary and alternative treatments for autism part 1: evidence-supported treatments. AMA J Ethics 17, 369-74.

Berry-Kravis, E., Des Portes, V., Hagerman, R., Jacquemont, S., Charles, P., Visootsak, J., Brinkman, M., Rerat, K., Koumaras, B., Zhu, L., Barth, G. M., Jaecklin, T., Apostol, G. \& von Raison, F. (2016). Mavoglurant in fragile X syndrome: Results of two randomized, double-blind, placebo-controlled trials. Sci Transl Med 8, 321ra5.

Bolton, P. F., Carcani-Rathwell, I., Hutton, J., Goode, S., Howlin, P. \& Rutter, M. (2011). Epilepsy in autism: features and correlates. Br J Psychiatry 198, 289-94.

Boyd, B. A., McDonough, S. G. \& Bodfish, J. W. (2012). Evidence-based behavioral 
interventions for repetitive behaviors in autism. J Autism Dev Disord 42, 1236-48.

Brainstorm, C., Anttila, V., Bulik-Sullivan, B., Finucane, H. K., Walters, R. K., Bras, J., Duncan, L., Escott-Price, V., Falcone, G. J., Gormley, P., Malik, R., Patsopoulos, N. A., Ripke, S., Wei, Z., Yu, D., Lee, P. H., Turley, P., Grenier-Boley, B., Chouraki, V., Kamatani, Y., Berr, C., Letenneur, L., Hannequin, D., Amouyel, P., Boland, A., Deleuze, J. F., Duron, E., Vardarajan, B. N., Reitz, C., Goate, A. M., Huentelman, M. J., Kamboh, M. I., Larson, E. B., Rogaeva, E., St George-Hyslop, P., Hakonarson, H., Kukull, W. A., Farrer, L. A., Barnes, L. L., Beach, T. G., Demirci, F. Y., Head, E., Hulette, C. M., Jicha, G. A., Kauwe, J. S. K., Kaye, J. A., Leverenz, J. B., Levey, A. I., Lieberman, A. P., Pankratz, V. S., Poon, W. W., Quinn, J. F., Saykin, A. J., Schneider, L. S., Smith, A. G., Sonnen, J. A., Stern, R. A., Van Deerlin, V. M., Van Eldik, L. J., Harold, D., Russo, G., Rubinsztein, D. C., Bayer, A., Tsolaki, M., Proitsi, P., Fox, N. C., Hampel, H., Owen, M. J., Mead, S., Passmore, P., Morgan, K., Nothen, M. M., Rossor, M., Lupton, M. K., Hoffmann, P., Kornhuber, J., Lawlor, B., McQuillin, A., Al-Chalabi, A., Bis, J. C., Ruiz, A., Boada, M., Seshadri, S., Beiser, A., Rice, K., van der Lee, S. J., De Jager, P. L., Geschwind, D. H., Riemenschneider, M., Riedel-Heller, S., Rotter, J. I., Ransmayr, G., Hyman, B. T., Cruchaga, C., Alegret, M., Winsvold, B., Palta, P., Farh, K. H., Cuenca-Leon, E., Furlotte, N., Kurth, T., Ligthart, L., Terwindt, G. M., Freilinger, T., Ran, C., Gordon, S. D., Borck, G., Adams, H. H. H., Lehtimaki, T., Wedenoja, J., Buring, J. E., Schurks, M., Hrafnsdottir, M., Hottenga, J. J., Penninx, B., Artto, V., Kaunisto, M., Vepsalainen, S., Martin, N. G., Montgomery, G. W., Kurki, M. I., Hamalainen, E., Huang, H., Huang, J., Sandor, C., Webber, C., Muller-Myhsok, B., Schreiber, S., Salomaa, V., Loehrer, E., Gobel, H., Macaya, A., Pozo-Rosich, P., Hansen, T., Werge, T., Kaprio, J., Metspalu, A., Kubisch, C., Ferrari, M. D., Belin, A. C., van den Maagdenberg, A., Zwart, J. A., Boomsma, D., Eriksson, N., Olesen, J., Chasman, D. I., Nyholt, D. R., Avbersek, A., Baum, L., Berkovic, S., Bradfield, J., Buono, R., Catarino, C. B., Cossette, P., De Jonghe, P., Depondt, C., Dlugos, D., Ferraro, T. N., French, J., Hjalgrim, H., Jamnadas-Khoda, J., Kalviainen, R., Kunz, W. S., Lerche, H., Leu, C., Lindhout, D., Lo, W., Lowenstein, D., McCormack, M., Moller, R. S., Molloy, A., Ng, P. W., Oliver, K., Privitera, M., Radtke, R., Ruppert, A. K., Sander, T., Schachter, S., Schankin, C., Scheffer, I., Schoch, S., Sisodiya, S. M., Smith, P., Sperling, M., Striano, P., Surges, R., Thomas, G. N., Visscher, F., Whelan, C. D., Zara, F., Heinzen, E. L., Marson, A., Becker, F., Stroink, H., Zimprich, F., Gasser, T., Gibbs, R., Heutink, P., 


\section{OSF preprint first posted online July 19, 2018; https://dx.doi.org/10.31219/osf.io/8z5rv \\ The copyright holders for this preprint (which was not peer-reviewed) are the authors}

Martinez, M., Morris, H. R., Sharma, M., Ryten, M., Mok, K. Y., Pulit, S., Bevan, S., Holliday, E., Attia, J., Battey, T., Boncoraglio, G., Thijs, V., Chen, W. M., Mitchell, B., Rothwell, P., Sharma, P., Sudlow, C., Vicente, A., Markus, H., Kourkoulis, C., Pera, J., Raffeld, M., Silliman, S., Boraska Perica, V., Thornton, L. M., Huckins, L. M., William Rayner, N., Lewis, C. M., Gratacos, M., Rybakowski, F., Keski-Rahkonen, A., Raevuori, A., Hudson, J. I., Reichborn-Kjennerud, T., Monteleone, P., Karwautz, A., Mannik, K., Baker, J. H., O'Toole, J. K., Trace, S. E., Davis, O. S. P., Helder, S. G., Ehrlich, S., Herpertz-Dahlmann, B., Danner, U. N., van Elburg, A. A., Clementi, M., Forzan, M., Docampo, E., Lissowska, J., Hauser, J., Tortorella, A., Maj, M., Gonidakis, F., Tziouvas, K., Papezova, H., Yilmaz, Z., Wagner, G., Cohen-Woods, S., Herms, S., Julia, A., Rabionet, R., Dick, D. M., Ripatti, S., Andreassen, O. A., Espeseth, T., Lundervold, A. J., Steen, V. M., Pinto, D., Scherer, S. W., Aschauer, H., Schosser, A., Alfredsson, L., Padyukov, L., Halmi, K. A., Mitchell, J., Strober, M., Bergen, A. W., Kaye, W., Szatkiewicz, J. P., Cormand, B., Ramos-Quiroga, J. A., Sanchez-Mora, C., Ribases, M., Casas, M., Hervas, A., Arranz, M. J., Haavik, J., Zayats, T., Johansson, S., Williams, N., Dempfle, A., Rothenberger, A., Kuntsi, J., Oades, R. D., Banaschewski, T., Franke, B., Buitelaar, J. K., Arias Vasquez, A., Doyle, A. E., Reif, A., Lesch, K. P., Freitag, C., Rivero, O., Palmason, H., Romanos, M., Langley, K., Rietschel, M., Witt, S. H., Dalsgaard, S., Borglum, A. D., Waldman, I., Wilmot, B., Molly, N., Bau, C. H. D., Crosbie, J., Schachar, R., Loo, S. K., McGough, J. J., Grevet, E. H., Medland, S. E., Robinson, E., Weiss, L. A., Bacchelli, E., Bailey, A., Bal, V., Battaglia, A., Betancur, C., Bolton, P., Cantor, R., Celestino-Soper, P., Dawson, G., De Rubeis, S., Duque, F., Green, A., Klauck, S. M., Leboyer, M., Levitt, P., Maestrini, E., Mane, S., De-Luca, D. M., Parr, J., Regan, R., Reichenberg, A., Sandin, S., Vorstman, J., Wassink, T., Wijsman, E., Cook, E., Santangelo, S., Delorme, R., Roge, B., Magalhaes, T., Arking, D., Schulze, T. G., Thompson, R. C., Strohmaier, J., Matthews, K., Melle, I., Morris, D., Blackwood, D., McIntosh, A., Bergen, S. E., Schalling, M., Jamain, S., Maaser, A., Fischer, S. B., Reinbold, C. S., Fullerton, J. M., Guzman-Parra, J., Mayoral, F., Schofield, P. R., Cichon, S., Muhleisen, T. W., Degenhardt, F., Schumacher, J., Bauer, M., Mitchell, P. B., Gershon, E. S., Rice, J., Potash, J. B., Zandi, P. P., Craddock, N., Ferrier, I. N., Alda, M., Rouleau, G. A., Turecki, G., Ophoff, R., Pato, C., Anjorin, A., Stahl, E., Leber, M., Czerski, P. M., Cruceanu, C., Jones, I. R., Posthuma, D., Andlauer, T. F. M., Forstner, A. J., Streit, F., Baune, B. T., Air, T., Sinnamon, G., Wray, N. R., Maclntyre, D. J., Porteous, 
D., Homuth, G., Rivera, M., Grove, J., Middeldorp, C. M., Hickie, I., Pergadia, M., Mehta, D., Smit, J. H., Jansen, R., de Geus, E., Dunn, E., Li, Q. S., Nauck, M., Schoevers, R. A., Beekman, A. T., Knowles, J. A., Viktorin, A., Arnold, P., Barr, C. L., Bedoya-Berrio, G., Bienvenu, O. J., Brentani, H., Burton, C., Camarena, B., Cappi, C., Cath, D., Cavallini, M., Cusi, D., Darrow, S., Denys, D., Derks, E. M., Dietrich, A., Fernandez, T., Figee, M., Freimer, N., Gerber, G., Grados, M., Greenberg, E., Hanna, G. L., Hartmann, A., Hirschtritt, M. E., Hoekstra, P. J., Huang, A., Huyser, C., Illmann, C., Jenike, M., Kuperman, S., Leventhal, B., Lochner, C., Lyon, G. J., Macciardi, F., Madruga-Garrido, M., Malaty, I. A., Maras, A., McGrath, L., Miguel, E. C., Mir, P., Nestadt, G., Nicolini, H., Okun, M. S., Pakstis, A., Paschou, P., Piacentini, J., Pittenger, C., Plessen, K., Ramensky, V., Ramos, E. M., Reus, V., Richter, M. A., Riddle, M. A., Robertson, M. M., Roessner, V., Rosario, M., Samuels, J. F., Sandor, P., Stein, D. J., Tsetsos, F., Van Nieuwerburgh, F., Weatherall, S., Wendland, J. R., Wolanczyk, T., Worbe, Y., Zai, G., Goes, F. S., McLaughlin, N., Nestadt, P. S., Grabe, H. J., Depienne, C., Konkashbaev, A., Lanzagorta, N., Valencia-Duarte, A., Bramon, E., Buccola, N., Cahn, W., Cairns, M., Chong, S. A., Cohen, D., Crespo-Facorro, B., Crowley, J., Davidson, M., DeLisi, L., Dinan, T., Donohoe, G., Drapeau, E., Duan, J., Haan, L., Hougaard, D., Karachanak-Yankova, S., Khrunin, A., Klovins, J., Kucinskas, V., Lee Chee Keong, J., Limborska, S., Loughland, C., Lonnqvist, J., Maher, B., Mattheisen, M., McDonald, C., Murphy, K. C., Nenadic, I., van Os, J., Pantelis, C., Pato, M., Petryshen, T., Quested, D., Roussos, P., Sanders, A. R., Schall, U., Schwab, S. G., Sim, K., So, H. C., Stogmann, E., Subramaniam, M., Toncheva, D., Waddington, J., Walters, J., Weiser, M., Cheng, W., Cloninger, R., Curtis, D., Gejman, P. V., Henskens, F., Mattingsdal, M., Oh, S. Y., Scott, R., Webb, B., Breen, G., Churchhouse, C., Bulik, C. M., Daly, M., Dichgans, M., Faraone, S. V., Guerreiro, R., Holmans, P., Kendler, K. S., Koeleman, B., Mathews, C. A., Price, A., Scharf, J., Sklar, P., Williams, J., Wood, N. W., Cotsapas, C., Palotie, A., Smoller, J. W., Sullivan, P., Rosand, J., Corvin, A. \& Neale, B. M. (2018). Analysis of shared heritability in common disorders of the brain. Science $\mathbf{3 6 0}$.

Bremer, E., Crozier, M. \& Lloyd, M. (2016). A systematic review of the behavioural outcomes following exercise interventions for children and youth with autism spectrum disorder. Autism 20, 899-915.

Brewer, N., Zoanetti, J. \& Young, R. L. (2017). The influence of media suggestions about links between criminality and autism spectrum disorder. Autism 21, 117-121. 
Brian, J. A., Smith, I. M., Zwaigenbaum, L. \& Bryson, S. E. (2017). Cross-site randomized control trial of the Social ABCs caregiver-mediated intervention for toddlers with autism spectrum disorder. Autism Res 10, 1700-1711.

Broady, T. R., Stoyles, G. J. \& Morse, C. (2017). Understanding carers' lived experience of stigma: the voice of families with a child on the autism spectrum. Health \& Social Care in the Community 25, 224-233.

Brondino, N., Fusar-Poli, L., Rocchetti, M., Provenzani, U., Barale, F. \& Politi, P. (2015). Complementary and Alternative Therapies for Autism Spectrum Disorder. Evid Based Complement Alternat Med 2015, 258589.

Brown, L. W., Camfield, P., Capers, M., Cascino, G., Ciccarelli, M., de Gusmao, C. M., Downs, S. M., Majnemer, A., Miller, A. B., SanInocencio, C., Schultz, R., Tilton, A., Winokur, A. \& Zupanc, M. (2016). The neurologist's role in supporting transition to adult health care: A consensus statement. Neurology 87, 835-40.

Brunsdon, V. E. \& Happe, F. (2014). Exploring the 'fractionation' of autism at the cognitive level. Autism 18, 17-30.

Buie, T., Campbell, D. B., Fuchs, G. J., 3rd, Furuta, G. T., Levy, J., Vandewater, J., Whitaker, A. H., Atkins, D., Bauman, M. L., Beaudet, A. L., Carr, E. G., Gershon, M. D., Hyman, S. L., Jirapinyo, P., Jyonouchi, H., Kooros, K., Kushak, R., Levitt, P., Levy, S. E., Lewis, J. D., Murray, K. F., Natowicz, M. R., Sabra, A., Wershil, B. K., Weston, S. C., Zeltzer, L. \& Winter, H. (2010a). Evaluation, diagnosis, and treatment of gastrointestinal disorders in individuals with ASDs: a consensus report. Pediatrics 125 Suppl 1, S1-18. Buie, T., Fuchs, G. J., 3rd, Furuta, G. T., Kooros, K., Levy, J., Lewis, J. D., Wershil, B. K. \& Winter, H. (2010b). Recommendations for evaluation and treatment of common gastrointestinal problems in children with ASDs. Pediatrics 125 Suppl 1, S19-29. Cachia, R. L., Anderson, A. \& Moore, D. W. (2016). Mindfulness in Individuals with Autism Spectrum Disorder: a Systematic Review and Narrative Analysis. Review Journal of Autism and Developmental Disorders 3, 165-178.

Cage, E., Di Monaco, J. \& Newell, V. (2018). Experiences of Autism Acceptance and Mental Health in Autistic Adults. J Autism Dev Disord 48, 473-484.

Carrasco, M., Volkmar, F. R. \& Bloch, M. H. (2012). Pharmacologic treatment of repetitive behaviors in autism spectrum disorders: evidence of publication bias. Pediatrics 129, e1301-10. 
Cassidy, S. \& Rodgers, J. (2017). Understanding and prevention of suicide in autism. Lancet Psychiatry 4, e11.

Chandler, D. L. (2016). Opening New Worlds for Those with Autism: Technology Is Creating Great New Possibilities for Those on Every Part of the Spectrum. IEEE Pulse 7, 43-6.

Chang, Y. C. \& Locke, J. (2016). A systematic review of peer-mediated interventions for children with autism spectrum disorder. Res Autism Spectr Disord 27, 1-10.

Chen, M. H., Pan, T. L., Lan, W. H., Hsu, J. W., Huang, K. L., Su, T. P., Li, C. T., Lin, W. C., Wei, H. T., Chen, T. J. \& Bai, Y. M. (2017). Risk of Suicide Attempts Among Adolescents and Young Adults With Autism Spectrum Disorder: A Nationwide Longitudinal Follow-Up Study. J Clin Psychiatry 78, e1174-e1179.

Cheuk, D. K., Wong, V. \& Chen, W. X. (2011). Acupuncture for autism spectrum disorders (ASD). Cochrane Database Syst Rev, CD007849.

Chiang, C. H., Chu, C. L. \& Lee, T. C. (2016). Efficacy of caregiver-mediated joint engagement intervention for young children with autism spectrum disorders. Autism 20, 172-82.

Ching, H. \& Pringsheim, T. (2012). Aripiprazole for autism spectrum disorders (ASD). Cochrane Database Syst Rev, CD009043.

Chugani, D. C., Chugani, H. T., Wiznitzer, M., Parikh, S., Evans, P. A., Hansen, R. L., Nass, R., Janisse, J. J., Dixon-Thomas, P., Behen, M., Rothermel, R., Parker, J. S., Kumar, A., Muzik, O., Edwards, D. J., Hirtz, D. \& Autism Center of Excellence, N. (2016). Efficacy of Low-Dose Buspirone for Restricted and Repetitive Behavior in Young Children with Autism Spectrum Disorder: A Randomized Trial. J Pediatr 170, 45-53 e1-4.

Coghlan, S., Horder, J., Inkster, B., Mendez, M. A., Murphy, D. G. \& Nutt, D. J. (2012). GABA system dysfunction in autism and related disorders: from synapse to symptoms. Neurosci Biobehav Rev 36, 2044-55.

Collins, F. S. \& Varmus, H. (2015). A new initiative on precision medicine. N Eng/J Med 372, 793-5.

Constantino, J. N. \& Charman, T. (2016). Diagnosis of autism spectrum disorder: reconciling the syndrome, its diverse origins, and variation in expression. Lancet Neurol 15, 279-91.

Constantino, J. N., Zhang, Y., Frazier, T., Abbacchi, A. M. \& Law, P. (2010). Sibling 
recurrence and the genetic epidemiology of autism. Am J Psychiatry 167, 1349-56.

Courchesne, V., Meilleur, A. A., Poulin-Lord, M. P., Dawson, M. \& Soulieres, I. (2015).

Autistic children at risk of being underestimated: school-based pilot study of a strength-informed assessment. Mol Autism 6, 12.

Croen, L. A., Zerbo, O., Qian, Y., Massolo, M. L., Rich, S., Sidney, S. \& Kripke, C. (2015). The health status of adults on the autism spectrum. Autism 19, 814-23.

Crowe, B. H. \& Salt, A. T. (2015). Autism: the management and support of children and young people on the autism spectrum (NICE Clinical Guideline 170). Arch Dis Child Educ Pract Ed 100, 20-3.

Davignon, M. N., Qian, Y., Massolo, M. \& Croen, L. A. (2018). Psychiatric and Medical Conditions in Transition-Aged Individuals With ASD. Pediatrics 141, S335-S345.

Dawson, M. (2004). The misbehaviour of behaviourists: Ethical challenges to the autism-ABA industry.

DeJong, H., Bunton, P. \& Hare, D. J. (2014). A systematic review of interventions used to treat catatonic symptoms in people with autistic spectrum disorders. J Autism Dev Disord 44, 2127-36.

DeMayo, M. M., Song, Y. J. C., Hickie, I. B. \& Guastella, A. J. (2017). A Review of the Safety, Efficacy and Mechanisms of Delivery of Nasal Oxytocin in Children: Therapeutic Potential for Autism and Prader-Willi Syndrome, and Recommendations for Future Research. Paediatr Drugs 19, 391-410.

Devinsky, O., Asato, M., Camfield, P., Geller, E., Kanner, A. M., Keller, S., Kerr, M., Kossoff, E. H., Lau, H., Kothare, S., Singh, B. K. \& Wirrell, E. (2015). Delivery of epilepsy care to adults with intellectual and developmental disabilities. Neurology 85, 1512-21.

Dewinter, J., De Graaf, H. \& Begeer, S. (2017). Sexual Orientation, Gender Identity, and Romantic Relationships in Adolescents and Adults with Autism Spectrum Disorder. J Autism Dev Disord 47, 2927-2934.

Dillon, S. R., Adams, D., Goudy, L., Bittner, M. \& McNamara, S. (2016). Evaluating Exercise as Evidence-Based Practice for Individuals with Autism Spectrum Disorder. Front Public Health 4, 290.

DiStefano, C., Shih, W., Kaiser, A., Landa, R. \& Kasari, C. (2016). Communication growth in minimally verbal children with ASD: The importance of interaction. Autism Res $\mathbf{9}$, 1093-1102. 
Dove, D., Warren, Z., McPheeters, M. L., Taylor, J. L., Sathe, N. A. \&

Veenstra-VanderWeele, J. (2012). Medications for adolescents and young adults with autism spectrum disorders: a systematic review. Pediatrics 130, 717-26.

Downs, J. M., Lechler, S., Dean, H., Sears, N., Patel, R., Shetty, H., Simonoff, E., Hotopf, M., Ford, T. J., Diaz-Caneja, C. M., Arango, C., MacCabe, J. H., Hayes, R. D. \&

Pina-Camacho, L. (2017). The Association Between Comorbid Autism Spectrum

Disorders and Antipsychotic Treatment Failure in Early-Onset Psychosis: A Historical Cohort Study Using Electronic Health Records. J Clin Psychiatry 78, e1233-e1241.

Dykens, E. M., Fisher, M. H., Taylor, J. L., Lambert, W. \& Miodrag, N. (2014). Reducing distress in mothers of children with autism and other disabilities: a randomized trial. Pediatrics 134, e454-63.

Eack, S. M., Hogarty, S. S., Greenwald, D. P., Litschge, M. Y., Porton, S. A., Mazefsky, C. A. \& Minshew, N. J. (2017). Cognitive enhancement therapy for adult autism spectrum disorder: Results of an 18-month randomized clinical trial. Autism Res 11, 519-530.

Elwyn, G., Frosch, D., Thomson, R., Joseph-Williams, N., Lloyd, A., Kinnersley, P., Cording, E., Tomson, D., Dodd, C., Rollnick, S., Edwards, A. \& Barry, M. (2012). Shared decision making: a model for clinical practice. J Gen Intern Med 27, 1361-7.

Estes, A., Munson, J., Rogers, S. J., Greenson, J., Winter, J. \& Dawson, G. (2015).

Long-Term Outcomes of Early Intervention in 6-Year-Old Children With Autism Spectrum Disorder. J Am Acad Child Adolesc Psychiatry 54, 580-7.

Feinberg, E., Augustyn, M., Fitzgerald, E., Sandler, J., Ferreira-Cesar Suarez, Z., Chen, N., Cabral, H., Beardslee, W. \& Silverstein, M. (2014). Improving maternal mental health after a child's diagnosis of autism spectrum disorder: results from a randomized clinical trial. JAMA Pediatr 168, 40-6.

Feinstein, A. (2010). A history of autism: Conversations with the pioneers. John Wiley \& Sons: Chichester, West Sussex, UK.

Fletcher-Watson, S., Larsen, K., Salomone, E. \& Members of the, C. E. W. G. (2017). What do parents of children with autism expect from participation in research? A community survey about early autism studies. Autism, 1362361317728436.

Fletcher-Watson, S., McConnell, F., Manola, E. \& McConachie, H. (2014). Interventions based on the Theory of Mind cognitive model for autism spectrum disorder (ASD). Cochrane Database Syst Rev, CD008785. 
Flippin, M., Reszka, S. \& Watson, L. R. (2010). Effectiveness of the Picture Exchange Communication System (PECS) on communication and speech for children with autism spectrum disorders: a meta-analysis. Am J Speech Lang Pathol 19, 178-95.

Frazier, T. W., Dawson, G., Murray, D., Shih, A., Sachs, J. S. \& Geiger, A. (2018). Brief Report: A Survey of Autism Research Priorities Across a Diverse Community of Stakeholders. J Autism Dev Disord.

Freckelton, I. (2013). Autism spectrum disorder: forensic issues and challenges for mental health professionals and courts. J Appl Res Intellect Disabil 26, 420-34.

French, L. \& Kennedy, E. M. M. (2017). Annual Research Review: Early intervention for infants and young children with, or at-risk of, autism spectrum disorder: a systematic review. J Child Psychol Psychiatry 59, 444-456.

Fung, L. K., Mahajan, R., Nozzolillo, A., Bernal, P., Krasner, A., Jo, B., Coury, D., Whitaker, A., Veenstra-Vanderweele, J. \& Hardan, A. Y. (2016). Pharmacologic Treatment of Severe Irritability and Problem Behaviors in Autism: A Systematic Review and Meta-analysis. Pediatrics 137 Suppl 2, S124-35.

Gates, J. A., Kang, E. \& Lerner, M. D. (2017). Efficacy of group social skills interventions for youth with autism spectrum disorder: A systematic review and meta-analysis. Clin Psychol Rev 52, 164-181.

Gelbar, N. W., Smith, I. \& Reichow, B. (2014). Systematic review of articles describing experience and supports of individuals with autism enrolled in college and university programs. J Autism Dev Disord 44, 2593-601.

Georgiades, S., Bishop, S. L. \& Frazier, T. (2017). Editorial Perspective: Longitudinal research in autism - introducing the concept of 'chronogeneity'. J Child Psychol Psychiatry 58, 634-636.

Geretsegger, M., Elefant, C., Mossler, K. A. \& Gold, C. (2014). Music therapy for people with autism spectrum disorder. Cochrane Database Syst Rev, CD004381.

Geschwind, D. H. \& State, M. W. (2015). Gene hunting in autism spectrum disorder: on the path to precision medicine. Lancet Neurol 14, 1109-20.

Gillespie-Lynch, K., Brooks, P. J., Someki, F., Obeid, R., Shane-Simpson, C., Kapp, S. K., Daou, N. \& Smith, D. S. (2015). Changing College Students' Conceptions of Autism: An Online Training to Increase Knowledge and Decrease Stigma. J Autism Dev Disord 45, 2553-66. 
Green, J., Charman, T., McConachie, H., Aldred, C., Slonims, V., Howlin, P., Le Couteur, A., Leadbitter, K., Hudry, K., Byford, S., Barrett, B., Temple, K., Macdonald, W. \& Pickles, A. (2010). Parent-mediated communication-focused treatment in children with autism (PACT): a randomised controlled trial. Lancet 375, 2152-60.

Green, J., Charman, T., Pickles, A., Wan, M. W., Elsabbagh, M., Slonims, V., Taylor, C., McNally, J., Booth, R., Gliga, T., Jones, E. J. H., Harrop, C., Bedford, R. \& Johnson, M. H. (2015). Parent-mediated intervention versus no intervention for infants at high risk of autism: a parallel, single-blind, randomised trial. The Lancet Psychiatry 2, 133-140.

Green, J. \& Garg, S. (2018). Annual Research Review: The state of autism intervention science: progress, target psychological and biological mechanisms and future prospects. J Child Psychol Psychiatry 59, 424-443.

Green, J., Pickles, A., Pasco, G., Bedford, R., Wan, M. W., Elsabbagh, M., Slonims, V., Gliga, T., Jones, E., Cheung, C., Charman, T., Johnson, M. \& British Autism Study of Infant Siblings, T. (2017). Randomised trial of a parent-mediated intervention for infants at high risk for autism: longitudinal outcomes to age 3 years. J Child Psychol Psychiatry 58, 1330-1340.

Grove, R., Hoekstra, R. A., Wierda, M. \& Begeer, S. (2018). Special interests and subjective wellbeing in autistic adults. Autism Res 11, 766-775.

Grynszpan, O., Weiss, P. L., Perez-Diaz, F. \& Gal, E. (2014). Innovative technology-based interventions for autism spectrum disorders: a meta-analysis. Autism 18, 346-61.

Guastella, A. J., Gray, K. M., Rinehart, N. J., Alvares, G. A., Tonge, B. J., Hickie, I. B., Keating, C. M., Cacciotti-Saija, C. \& Einfeld, S. L. (2015). The effects of a course of intranasal oxytocin on social behaviors in youth diagnosed with autism spectrum disorders: a randomized controlled trial. J Child Psychol Psychiatry 56, 444-52.

Guastella, A. J. \& Hickie, I. B. (2016). Oxytocin Treatment, Circuitry, and Autism: A Critical Review of the Literature Placing Oxytocin Into the Autism Context. Biol Psychiatry 79, 234-42.

Handen, B. L., Anagnostou, E., Aman, M. G., Sanders, K. B., Chan, J., Hollway, J. A., Brian, J., Arnold, L. E., Capano, L., Williams, C., Hellings, J. A., Butter, E., Mankad, D., Tumuluru, R., Kettel, J., Newsom, C. R., Peleg, N., Odrobina, D., McAuliffe-Bellin, S., Marler, S., Wong, T., Wagner, A., Hadjiyannakis, S., Macklin, E. A. \& Veenstra-VanderWeele, J. (2017). A Randomized, Placebo-Controlled Trial of Metformin 
for the Treatment of Overweight Induced by Antipsychotic Medication in Young People With Autism Spectrum Disorder: Open-Label Extension. J Am Acad Child Adolesc Psychiatry 56, 849-856 e6.

Happe, F. \& Charlton, R. A. (2012). Aging in autism spectrum disorders: a mini-review. Gerontology 58, 70-8.

Happe, F. \& Vital, P. (2009). What aspects of autism predispose to talent? Philos Trans $R$ Soc Lond B Biol Sci 364, 1369-75.

Harrop, C. (2015). Evidence-based, parent-mediated interventions for young children with autism spectrum disorder: The case of restricted and repetitive behaviors. Autism 19, 662-72.

Healy, S., Nacario, A., Braithwaite, R. E. \& Hopper, C. (2018). The effect of physical activity interventions on youth with autism spectrum disorder: A meta-analysis. Autism Res 11, 818-833.

Heasman, B. \& Gillespie, A. (2017). Perspective-taking is two-sided: Misunderstandings between people with Asperger's syndrome and their family members. Autism, 1362361317708287.

Hedges, S. H., Odom, S. L., Hume, K. \& Sam, A. (2018). Technology use as a support tool by secondary students with autism. Autism 22, 70-79.

Helles, A., Gillberg, I. C., Gillberg, C. \& Billstedt, E. (2017). Asperger syndrome in males over two decades: Quality of life in relation to diagnostic stability and psychiatric comorbidity. Autism 21, 458-469.

Hirota, T., Veenstra-Vanderweele, J., Hollander, E. \& Kishi, T. (2014). Antiepileptic medications in autism spectrum disorder: a systematic review and meta-analysis. $J$ Autism Dev Disord 44, 948-57.

Hirsch, L. E. \& Pringsheim, T. (2016). Aripiprazole for autism spectrum disorders (ASD). Cochrane Database Syst Rev, CD009043.

Holton, A. E., Farrell, L. C. \& Fudge, J. L. (2014). A Threatening Space?: Stigmatization and the Framing of Autism in the News. Communication Studies 65, 189-207.

Hoover, D. W. \& Kaufman, J. (2018). Adverse childhood experiences in children with autism spectrum disorder. Curr Opin Psychiatry 31, 128-132.

Horvath, A., Lukasik, J. \& Szajewska, H. (2017). omega-3 Fatty Acid Supplementation Does Not Affect Autism Spectrum Disorder in Children: A Systematic Review and 
Meta-Analysis. J Nutr 147, 367-376.

Hotton, M. \& Coles, S. (2016). The Effectiveness of Social Skills Training Groups for Individuals with Autism Spectrum Disorder. Review Journal of Autism and Developmental Disorders 3, 68-81.

Howes, O. D., Rogdaki, M., Findon, J. L., Wichers, R. H., Charman, T., King, B. H., Loth, E., McAlonan, G. M., McCracken, J. T., Parr, J. R., Povey, C., Santosh, P., Wallace, S., Simonoff, E. \& Murphy, D. G. (2018). Autism spectrum disorder: Consensus guidelines on assessment, treatment and research from the British Association for Psychopharmacology. J Psychopharmacol 32, 3-29.

Howlin, P. \& Magiati, I. (2017). Autism spectrum disorder: outcomes in adulthood. Curr Opin Psychiatry 30, 69-76.

Howlin, P. \& Moss, P. (2012). Adults with autism spectrum disorders. Can J Psychiatry 57, 275-83.

Hurwitz, R., Blackmore, R., Hazell, P., Williams, K. \& Woolfenden, S. (2012). Tricyclic antidepressants for autism spectrum disorders (ASD) in children and adolescents. Cochrane Database Syst Rev, CD008372.

Huws, J. C. \& Jones, R. S. P. (2011). Missing voices: representations of autism in British newspapers, 1999-2008. British Journal of Learning Disabilities 39, 98-104.

lacono, T., Trembath, D. \& Erickson, S. (2016). The role of augmentative and alternative communication for children with autism: current status and future trends. Neuropsychiatr Dis Treat 12, 2349-2361.

Jacob, A., Scott, M., Falkmer, M. \& Falkmer, T. (2015). The Costs and Benefits of Employing an Adult with Autism Spectrum Disorder: A Systematic Review. PLoS One 10, e0139896.

James, S., Montgomery, P. \& Williams, K. (2011). Omega-3 fatty acids supplementation for autism spectrum disorders (ASD). Cochrane Database Syst Rev, CD007992.

James, S., Stevenson, S. W., Silove, N. \& Williams, K. (2015). Chelation for autism spectrum disorder (ASD). Cochrane Database Syst Rev 5, CD010766.

Jesner, O. S., Aref-Adib, M. \& Coren, E. (2007). Risperidone for autism spectrum disorder. Cochrane Database Syst Rev, CD005040.

Jobski, K., Hofer, J., Hoffmann, F. \& Bachmann, C. (2017). Use of psychotropic drugs in patients with autism spectrum disorders: a systematic review. Acta Psychiatr Scand 135, 
8-28.

Johnson, T. D. \& Joshi, A. (2016). Dark clouds or silver linings? A stigma threat perspective on the implications of an autism diagnosis for workplace well-being. J Appl Psychol 101, 430-49.

Jokiranta, E., Sourander, A., Suominen, A., Timonen-Soivio, L., Brown, A. S. \& Sillanpaa, M. (2014). Epilepsy among children and adolescents with autism spectrum disorders: a population-based study. J Autism Dev Disord 44, 2547-57.

Jones, E. J. H., Dawson, G., Kelly, J., Estes, A. \& Jane Webb, S. (2017a). Parent-delivered early intervention in infants at risk for ASD: Effects on electrophysiological and habituation measures of social attention. Autism Res 10, 961-972.

Jones, K. B., Cottle, K., Bakian, A., Farley, M., Bilder, D., Coon, H. \& McMahon, W. M. (2016). A description of medical conditions in adults with autism spectrum disorder: $A$ follow-up of the 1980s Utah/UCLA Autism Epidemiologic Study. Autism 20, 551-61. Jones, R. A., Downing, K., Rinehart, N. J., Barnett, L. M., May, T., McGillivray, J. A., Papadopoulos, N. V., Skouteris, H., Timperio, A. \& Hinkley, T. (2017b). Physical activity, sedentary behavior and their correlates in children with Autism Spectrum Disorder: A systematic review. PLoS One 12, e0172482.

Jonsson, U., Choque Olsson, N. \& Bolte, S. (2016). Can findings from randomized controlled trials of social skills training in autism spectrum disorder be generalized? The neglected dimension of external validity. Autism 20, 295-305.

Kanner, L. (1943). Autistic disturbances of affective contact. Nervous Child 2, 217-50. Karkhaneh, M., Clark, B., Ospina, M. B., Seida, J. C., Smith, V. \& Hartling, L. (2010). Social Stories to improve social skills in children with autism spectrum disorder: a systematic review. Autism 14, 641-62.

Kasari, C., Brady, N., Lord, C. \& Tager-Flusberg, H. (2013). Assessing the minimally verbal school-aged child with autism spectrum disorder. Autism Res 6, 479-93.

Kasari, C., Gulsrud, A., Freeman, S., Paparella, T. \& Hellemann, G. (2012). Longitudinal follow-up of children with autism receiving targeted interventions on joint attention and play. J Am Acad Child Adolesc Psychiatry 51, 487-95.

Kasari, C., Kaiser, A., Goods, K., Nietfeld, J., Mathy, P., Landa, R., Murphy, S. \& Almirall, D. (2014a). Communication interventions for minimally verbal children with autism: a sequential multiple assignment randomized trial. J Am Acad Child Adolesc Psychiatry 53, 
635-46.

Kasari, C., Lawton, K., Shih, W., Barker, T. V., Landa, R., Lord, C., Orlich, F., King, B., Wetherby, A. \& Senturk, D. (2014b). Caregiver-mediated intervention for low-resourced preschoolers with autism: an RCT. Pediatrics 134, e72-9.

Kasari, C. \& Patterson, S. (2012). Interventions addressing social impairment in autism. Curr Psychiatry Rep 14, 713-25.

Kasari, C., Shire, S., Factor, R. \& McCracken, C. (2014c). Psychosocial treatments for individuals with autism spectrum disorder across the lifespan: new developments and underlying mechanisms. Curr Psychiatry Rep 16, 512.

Kearney, H. M., South, S. T., Wolff, D. J., Lamb, A., Hamosh, A., Rao, K. W. \& Working Group of the American College of Medical, G. (2011a). American College of Medical Genetics recommendations for the design and performance expectations for clinical genomic copy number microarrays intended for use in the postnatal setting for detection of constitutional abnormalities. Genet Med 13, 676-9.

Kearney, H. M., Thorland, E. C., Brown, K. K., Quintero-Rivera, F., South, S. T. \& Working Group of the American College of Medical Genetics Laboratory Quality Assurance, C. (2011b). American College of Medical Genetics standards and guidelines for interpretation and reporting of postnatal constitutional copy number variants. Genet Med 13, 680-5.

Kenny, L., Hattersley, C., Molins, B., Buckley, C., Povey, C. \& Pellicano, E. (2016). Which terms should be used to describe autism? Perspectives from the UK autism community. Autism 20, 442-62.

Kinnear, S. H., Link, B. G., Ballan, M. S. \& Fischbach, R. L. (2016). Understanding the Experience of Stigma for Parents of Children with Autism Spectrum Disorder and the Role Stigma Plays in Families' Lives. J Autism Dev Disord 46, 942-53.

Koegel, R., Kim, S., Koegel, L. \& Schwartzman, B. (2013). Improving socialization for high school students with ASD by using their preferred interests. J Autism Dev Disord 43, 2121-34.

Koenig, K. P. \& Williams, L. H. (2017). Characterization and Utilization of Preferred Interests: A Survey of Adults on the Autism Spectrum. Occupational Therapy in Mental Health 33, 129-140.

Kohane, I. S., McMurry, A., Weber, G., MacFadden, D., Rappaport, L., Kunkel, L., Bickel, 
J., Wattanasin, N., Spence, S., Murphy, S. \& Churchill, S. (2012). The co-morbidity burden of children and young adults with autism spectrum disorders. PLOS ONE 7, e33224.

Kose, L. K., Fox, L. \& Storch, E. A. (2018). Effectiveness of Cognitive Behavioral Therapy for Individuals with Autism Spectrum Disorders and Comorbid Obsessive-Compulsive Disorder: A Review of the Research. J Dev Phys Disabil 30, 69-87.

Lai, M. C. \& Baron-Cohen, S. (2015). Identifying the lost generation of adults with autism spectrum conditions. Lancet Psychiatry 2, 1013-27.

Lai, M. C., Lombardo, M. V., Auyeung, B., Chakrabarti, B. \& Baron-Cohen, S. (2015). Sex/gender differences and autism: setting the scene for future research. J Am Acad Child Adolesc Psychiatry 54, 11-24.

Lai, M. C., Lombardo, M. V. \& Baron-Cohen, S. (2014). Autism. Lancet 383, 896-910. Lai, M. C., Lombardo, M. V., Chakrabarti, B. \& Baron-Cohen, S. (2013). Subgrouping the Autism "Spectrum": Reflections on DSM-5. PLoS Biol 11, e1001544.

Lee, B., Lee, J., Cheon, J. H., Sung, H. K., Cho, S. H. \& Chang, G. T. (2018). The Efficacy and Safety of Acupuncture for the Treatment of Children with Autism Spectrum Disorder: A Systematic Review and Meta-Analysis. Evid Based Complement Alternat Med 2018, 1057539.

Lee, M. S., Kim, J. I. \& Ernst, E. (2011). Massage therapy for children with autism spectrum disorders: a systematic review. J Clin Psychiatry 72, 406-11.

Lin, L. Y. \& Huang, P. C. (2017). Quality of life and its related factors for adults with autism spectrum disorder. Disabil Rehabil, 1-8.

Lindsay, S., Hounsell, K. G. \& Cassiani, C. (2017). A scoping review of the role of LEGO((R)) therapy for improving inclusion and social skills among children and youth with autism. Disabil Health J 10, 173-182.

Liu, K. Y., King, M. \& Bearman, P. S. (2010). Social influence and the autism epidemic. AJS 115, 1387-434.

Livingston, L. A. \& Happe, F. (2017). Conceptualising compensation in neurodevelopmental disorders: Reflections from autism spectrum disorder. Neurosci Biobehav Rev 80, 729-742.

Lombardo, M. V., Lai, M.-C. \& Baron-Cohen, S. (2018). Big data approaches to decomposing heterogeneity across the autism spectrum. bioRxiv. 
Loomes, R., Hull, L. \& Mandy, W. P. L. (2017). What Is the Male-to-Female Ratio in Autism Spectrum Disorder? A Systematic Review and Meta-Analysis. J Am Acad Child Adolesc Psychiatry 56, 466-474.

Lorah, E. R., Parnell, A., Whitby, P. S. \& Hantula, D. (2015). A Systematic Review of Tablet Computers and Portable Media Players as Speech Generating Devices for Individuals with Autism Spectrum Disorder. J Autism Dev Disord 45, 3792-804.

Loth, E., Charman, T., Mason, L., Tillmann, J., Jones, E. J. H., Wooldridge, C., Ahmad, J., Auyeung, B., Brogna, C., Ambrosino, S., Banaschewski, T., Baron-Cohen, S., Baumeister, S., Beckmann, C., Brammer, M., Brandeis, D., Bolte, S., Bourgeron, T., Bours, C., de Bruijn, Y., Chakrabarti, B., Crawley, D., Cornelissen, I., Acqua, F. D., Dumas, G., Durston, S., Ecker, C., Faulkner, J., Frouin, V., Garces, P., Goyard, D., Hayward, H., Ham, L. M., Hipp, J., Holt, R. J., Johnson, M. H., Isaksson, J., Kundu, P., Lai, M. C., D'Ardhuy X, L., Lombardo, M. V., Lythgoe, D. J., Mandl, R., Meyer-Lindenberg, A., Moessnang, C., Mueller, N., O'Dwyer, L., Oldehinkel, M., Oranje, B., Pandina, G., Persico, A. M., Ruigrok, A. N. V., Ruggeri, B., Sabet, J., Sacco, R., Caceres, A. S. J., Simonoff, E., Toro, R., Tost, H., Waldman, J., Williams, S. C. R., Zwiers, M. P., Spooren, W., Murphy, D. G. M. \& Buitelaar, J. K. (2017). The EU-AIMS Longitudinal European Autism Project (LEAP): design and methodologies to identify and validate stratification biomarkers for autism spectrum disorders. Mol Autism 8, 24.

Loth, E., Murphy, D. G. \& Spooren, W. (2016). Defining Precision Medicine Approaches to Autism Spectrum Disorders: Concepts and Challenges. Front Psychiatry 7, 188.

Lundstrom, S., Reichenberg, A., Melke, J., Rastam, M., Kerekes, N., Lichtenstein, P., Gillberg, C. \& Anckarsater, H. (2015). Autism spectrum disorders and coexisting disorders in a nationwide Swedish twin study. J Child Psychol Psychiatry 56, 702-10. Lunsky, Y., R, P. H., Weiss, J. A., A, M. P., Hutton, S. \& White, K. (2017). Comparative Effects of Mindfulness and Support and Information Group Interventions for Parents of Adults with Autism Spectrum Disorder and Other Developmental Disabilities. J Autism Dev Disord 47, 1769-1779.

Lyall, K., Croen, L., Daniels, J., Fallin, M. D., Ladd-Acosta, C., Lee, B. K., Park, B. Y., Snyder, N. W., Schendel, D., Volk, H., Windham, G. C. \& Newschaffer, C. (2017). The Changing Epidemiology of Autism Spectrum Disorders. Annu Rev Public Health 38, 81-102. 
Mahajan, R., Bernal, M. P., Panzer, R., Whitaker, A., Roberts, W., Handen, B., Hardan, A., Anagnostou, E. \& Veenstra-VanderWeele, J. (2012). Clinical practice pathways for evaluation and medication choice for attention-deficit/hyperactivity disorder symptoms in autism spectrum disorders. Pediatrics 130 Suppl 2, S125-38.

Malow, B. A., Byars, K., Johnson, K., Weiss, S., Bernal, P., Goldman, S. E., Panzer, R., Coury, D. L. \& Glaze, D. G. (2012). A practice pathway for the identification, evaluation, and management of insomnia in children and adolescents with autism spectrum disorders. Pediatrics 130 Suppl 2, S106-24.

Mandy, W. \& Lai, M. C. (2016). Annual Research Review: The role of the environment in the developmental psychopathology of autism spectrum condition. J Child Psychol Psychiatry 57, 271-92.

Manning, M., Hudgins, L., Professional, P. \& Guidelines, C. (2010). Array-based technology and recommendations for utilization in medical genetics practice for detection of chromosomal abnormalities. Genet Med 12, 742-5.

Marcus, R. N., Owen, R., Kamen, L., Manos, G., McQuade, R. D., Carson, W. H. \& Aman, M. G. (2009). A placebo-controlled, fixed-dose study of aripiprazole in children and adolescents with irritability associated with autistic disorder. J Am Acad Child Adolesc Psychiatry 48, 1110-9.

Mazefsky, C. A. \& White, S. W. (2014). Emotion regulation: concepts \& practice in autism spectrum disorder. Child Adolesc Psychiatr Clin N Am 23, 15-24.

Mazurek, M. O., Vasa, R. A., Kalb, L. G., Kanne, S. M., Rosenberg, D., Keefer, A., Murray, D. S., Freedman, B. \& Lowery, L. A. (2013). Anxiety, sensory over-responsivity, and gastrointestinal problems in children with autism spectrum disorders. J Abnorm Child Psychol 41, 165-76.

McCracken, J. T., McGough, J., Shah, B., Cronin, P., Hong, D., Aman, M. G., Arnold, L. E., Lindsay, R., Nash, P., Hollway, J., McDougle, C. J., Posey, D., Swiezy, N., Kohn, A., Scahill, L., Martin, A., Koenig, K., Volkmar, F., Carroll, D., Lancor, A., Tierney, E., Ghuman, J., Gonzalez, N. M., Grados, M., Vitiello, B., Ritz, L., Davies, M., Robinson, J. \& McMahon, D. (2002). Risperidone in children with autism and serious behavioral problems. N Engl J Med 347, 314-21.

McGuire, K., Fung, L. K., Hagopian, L., Vasa, R. A., Mahajan, R., Bernal, P., Silberman, A. E., Wolfe, A., Coury, D. L., Hardan, A. Y., Veenstra-VanderWeele, J. \& Whitaker, A. H. 
(2016). Irritability and Problem Behavior in Autism Spectrum Disorder: A Practice Pathway for Pediatric Primary Care. Pediatrics 137 Suppl 2, S136-48.

McVey, A. J., Schiltz, H., Haendel, A., Dolan, B. K., Willar, K. S., Pleiss, S., Karst, J. S., Carson, A. M., Caiozzo, C., Vogt, E. \& Van Hecke, A. V. (2017). Brief Report: Does Gender Matter in Intervention for ASD? Examining the Impact of the PEERS(R) Social Skills Intervention on Social Behavior Among Females with ASD. J Autism Dev Disord 47, 2282-2289.

Mesibov, G. B. \& Shea, V. (2010). The TEACCH program in the era of evidence-based practice. J Autism Dev Disord 40, 570-9.

Millward, C., Ferriter, M., Calver, S. \& Connell-Jones, G. (2008). Gluten- and casein-free diets for autistic spectrum disorder. Cochrane Database Syst Rev, CD003498.

Morin, K. L., Ganz, J. B., Gregori, E. V., Foster, M. J., Gerow, S. L., Genc-Tosun, D. \& Hong, E. R. (2018). A systematic quality review of high-tech AAC interventions as an evidence-based practice. Augment Altern Commun, 1-14.

Mottron, L. (2017). Should we change targets and methods of early intervention in autism, in favor of a strengths-based education? Eur Child Adolesc Psychiatry 26, 815-825.

Muller, C. L., Anacker, A. M. J. \& Veenstra-VanderWeele, J. (2016). The serotonin system in autism spectrum disorder: From biomarker to animal models. Neuroscience 321, 24-41.

Murza, K. A., Schwartz, J. B., Hahs-Vaughn, D. L. \& Nye, C. (2016). Joint attention interventions for children with autism spectrum disorder: a systematic review and meta-analysis. Int J Lang Commun Disord 51, 236-51.

Muskens, J. B., Velders, F. P. \& Staal, W. G. (2017). Medical comorbidities in children and adolescents with autism spectrum disorders and attention deficit hyperactivity disorders: a systematic review. Eur Child Adolesc Psychiatry 26, 1093-1103.

Nevill, R. E., Lecavalier, L. \& Stratis, E. A. (2016). Meta-analysis of parent-mediated interventions for young children with autism spectrum disorder. Autism $\mathbf{0}$, 1362361316677838.

Nicholas, D. B., Attridge, M., Zwaigenbaum, L. \& Clarke, M. (2015). Vocational support approaches in autism spectrum disorder: a synthesis review of the literature. Autism 19, 235-45. 
Nicholas, D. B., Mitchell, W., Dudley, C., Clarke, M. \& Zulla, R. (2018). An Ecosystem Approach to Employment and Autism Spectrum Disorder. J Autism Dev Disord 48, 264-275.

Nicolaidis, C., Kripke, C. C. \& Raymaker, D. (2014). Primary care for adults on the autism spectrum. Med Clin North Am 98, 1169-91.

Nye, C. \& Brice, A. (2005). Combined vitamin B6-magnesium treatment in autism spectrum disorder. Cochrane Database Syst Rev, CD003497.

O'Haire, M. E. (2013). Animal-assisted intervention for autism spectrum disorder: a systematic literature review. J Autism Dev Disord 43, 1606-22.

Oberman, L. M., Enticott, P. G., Casanova, M. F., Rotenberg, A., Pascual-Leone, A., McCracken, J. T. \& Group, T. M. S. i. A. C. (2016). Transcranial magnetic stimulation in autism spectrum disorder: Challenges, promise, and roadmap for future research. Autism Res 9, 184-203.

Odom, S., Hume, K., Boyd, B. \& Stabel, A. (2012). Moving beyond the intensive behavior treatment versus eclectic dichotomy: evidence-based and individualized programs for learners with ASD. Behav Modif 36, 270-97.

Okamoto, Y., Ishitobi, M., Wada, Y. \& Kosaka, H. (2016). The Potential of Nasal Oxytocin Administration for Remediation of Autism Spectrum Disorders. CNS Neurol Disord Drug Targets 15, 564-77.

Oliver, C., Licence, L. \& Richards, C. (2017). Self-injurious behaviour in people with intellectual disability and autism spectrum disorder. Curr Opin Psychiatry 30, 97-101.

Ooi, Y. P., Weng, S. J., Kossowsky, J., Gerger, H. \& Sung, M. (2017). Oxytocin and Autism Spectrum Disorders: A Systematic Review and Meta-Analysis of Randomized Controlled Trials. Pharmacopsychiatry 50, 5-13.

Oono, I. P., Honey, E. J. \& McConachie, H. (2013). Parent-mediated early intervention for young children with autism spectrum disorders (ASD). Cochrane Database Syst Rev 4, CD009774.

Park, S. Y., Cervesi, C., Galling, B., Molteni, S., Walyzada, F., Ameis, S. H., Gerhard, T., Olfson, M. \& Correll, C. U. (2016). Antipsychotic Use Trends in Youth With Autism Spectrum Disorder and/or Intellectual Disability: A Meta-Analysis. J Am Acad Child Adolesc Psychiatry 55, 456-468 e4.

Parker, K. J., Oztan, O., Libove, R. A., Sumiyoshi, R. D., Jackson, L. P., Karhson, D. S., 
Summers, J. E., Hinman, K. E., Motonaga, K. S., Phillips, J. M., Carson, D. S., Garner, J. P. \& Hardan, A. Y. (2017). Intranasal oxytocin treatment for social deficits and biomarkers of response in children with autism. Proc Natl Acad Sci U S A 114, 8119-8124.

Parsons, D., Cordier, R., Vaz, S. \& Lee, H. C. (2017a). Parent-Mediated Intervention Training Delivered Remotely for Children With Autism Spectrum Disorder Living Outside of Urban Areas: Systematic Review. J Med Internet Res 19, e198.

Parsons, L., Cordier, R., Munro, N., Joosten, A. \& Speyer, R. (2017b). A systematic review of pragmatic language interventions for children with autism spectrum disorder. PLoS One 12, e0172242.

Patterson, S. Y., Smith, V. \& Mirenda, P. (2012). A systematic review of training programs for parents of children with autism spectrum disorders: single subject contributions. Autism 16, 498-522.

Pellicano, E., Dinsmore, A. \& Charman, T. (2014). What should autism research focus upon? Community views and priorities from the United Kingdom. Autism 18, 756-70. Pellicano, L., Bolte, S. \& Stahmer, A. (2018). The current illusion of educational inclusion. Autism 22, 386-387.

Pennisi, P., Tonacci, A., Tartarisco, G., Billeci, L., Ruta, L., Gangemi, S. \& Pioggia, G. (2016). Autism and social robotics: A systematic review. Autism Res 9, 165-83.

Perkins, E. A. \& Berkman, K. A. (2012). Into the unknown: aging with autism spectrum disorders. Am J Intellect Dev Disabil 117, 478-96.

Pickles, A., Le Couteur, A., Leadbitter, K., Salomone, E., Cole-Fletcher, R., Tobin, H., Gammer, I., Lowry, J., Vamvakas, G., Byford, S., Aldred, C., Slonims, V., McConachie, H., Howlin, P., Parr, J. R., Charman, T. \& Green, J. (2016). Parent-mediated social communication therapy for young children with autism (PACT): long-term follow-up of a randomised controlled trial. Lancet 388, 2501-2509.

Pickles, A., Starr, E., Kazak, S., Bolton, P., Papanikolaou, K., Bailey, A., Goodman, R. \& Rutter, M. (2000). Variable expression of the autism broader phenotype: findings from extended pedigrees. J Child Psychol Psychiatry 41, 491-502.

Pilling, S., Baron-Cohen, S., Megnin-Viggars, O., Lee, R. \& Taylor, C. (2012). Recognition, referral, diagnosis, and management of adults with autism: summary of NICE guidance. Bmj 344, e4082.

Piven, J., Palmer, P., Jacobi, D., Childress, D. \& Arndt, S. (1997). Broader autism 
phenotype: evidence from a family history study of multiple-incidence autism families. Am J Psychiatry 154, 185-90.

Piwowarczyk, A., Horvath, A., Lukasik, J., Pisula, E. \& Szajewska, H. (2018). Gluten- and casein-free diet and autism spectrum disorders in children: a systematic review. Eur J Nutr 57, 433-440.

Poslawsky, I. E., Naber, F. B., Bakermans-Kranenburg, M. J., van Daalen, E., van Engeland, H. \& van, I. M. H. (2015). Video-feedback Intervention to promote Positive Parenting adapted to Autism (VIPP-AUTI): A randomized controlled trial. Autism 19, 588-603.

Prizant, B. M. \& Wetherby, A. M. (1998). Understanding the continuum of discrete-trial traditional behavioral to social-pragmatic developmental approaches in communication enhancement for young children with autism/PDD. Semin Speech Lang 19, 329-52; quiz $353 ; 424$.

Rahman, A., Divan, G., Hamdani, S. U., Vajaratkar, V., Taylor, C., Leadbitter, K., Aldred, C., Minhas, A., Cardozo, P., Emsley, R., Patel, V. \& Green, J. (2016). Effectiveness of the parent-mediated intervention for children with autism spectrum disorder in south Asia in India and Pakistan (PASS): a randomised controlled trial. Lancet Psychiatry 3, 128-36. Ranson, N. J. \& Byrne, M. K. (2014). Promoting peer acceptance of females with higher-functioning autism in a mainstream education setting: a replication and extension of the effects of an autism anti-stigma program. J Autism Dev Disord 44, 2778-96.

Ratto, A. B. \& Mesibov, G. B. (2015). Autism spectrum disorders in adolescence and adulthood: Long-term outcomes and relevant issues for treatment and research. Sci China Life Sci 58, 1010-5.

Reichow, B., Barton, E. E., Boyd, B. A. \& Hume, K. (2012a). Early intensive behavioral intervention (EIBI) for young children with autism spectrum disorders (ASD). Cochrane Database Syst Rev 10, CD009260.

Reichow, B., Hume, K., Barton, E. E. \& Boyd, B. A. (2018). Early intensive behavioral intervention (EIBI) for young children with autism spectrum disorders (ASD). Cochrane Database Syst Rev 5, CD009260.

Reichow, B., Steiner, A. M. \& Volkmar, F. (2012b). Social skills groups for people aged 6 to 21 with autism spectrum disorders (ASD). Cochrane Database Syst Rev 7, CD008511. Richards, C., Jones, C., Groves, L., Moss, J. \& Oliver, C. (2015). Prevalence of autism 
spectrum disorder phenomenology in genetic disorders: a systematic review and meta-analysis. Lancet Psychiatry 2, 909-16.

Robinson, E. B., St Pourcain, B., Anttila, V., Kosmicki, J. A., Bulik-Sullivan, B., Grove, J., Maller, J., Samocha, K. E., Sanders, S. J., Ripke, S., Martin, J., Hollegaard, M. V., Werge, T., Hougaard, D. M., i, P.-S. S. I. B. A. G., Neale, B. M., Evans, D. M., Skuse, D.,

Mortensen, P. B., Borglum, A. D., Ronald, A., Smith, G. D. \& Daly, M. J. (2016). Genetic risk for autism spectrum disorders and neuropsychiatric variation in the general population. Nat Genet 48, 552-5.

Rogers, S. J., Dawson, G. \& Vismara, L. A. (2012). An early start for your child with autism: Using everyday activities to help kids connect, communicate, and learn. Guilford Press.

Rubenstein, J. L. \& Merzenich, M. M. (2003). Model of autism: increased ratio of excitation/inhibition in key neural systems. Genes Brain Behav 2, 255-67.

Russell, G., Starr, S., Elphick, C., Rodogno, R. \& Singh, I. (2018). Selective patient and public involvement: The promise and perils of pharmaceutical intervention for autism. Health Expect 21, 466-473.

Ruzich, E., Allison, C., Smith, P., Watson, P., Auyeung, B., Ring, H. \& Baron-Cohen, S. (2015). Measuring autistic traits in the general population: a systematic review of the Autism-Spectrum Quotient (AQ) in a nonclinical population sample of 6,900 typical adult males and females. Mol Autism 6, 2.

Sameroff, A. J. \& Mackenzie, M. J. (2003). Research strategies for capturing transactional models of development: the limits of the possible. Dev Psychopathol 15, 613-40.

Sasson, N. J., Faso, D. J., Nugent, J., Lovell, S., Kennedy, D. P. \& Grossman, R. B. (2017). Neurotypical Peers are Less Willing to Interact with Those with Autism based on Thin Slice Judgments. Sci Rep 7, 40700.

Sasson, N. J. \& Morrison, K. E. (2017). First impressions of adults with autism improve with diagnostic disclosure and increased autism knowledge of peers. Autism, 1362361317729526.

Sathe, N., Andrews, J. C., McPheeters, M. L. \& Warren, Z. E. (2017). Nutritional and Dietary Interventions for Autism Spectrum Disorder: A Systematic Review. Pediatrics 139. 
Schaaf, R. C. \& Lane, A. E. (2015). Toward a Best-Practice Protocol for Assessment of Sensory Features in ASD. J Autism Dev Disord 45, 1380-95.

Schendel, D. E., Overgaard, M., Christensen, J., Hjort, L., Jorgensen, M., Vestergaard, M. \& Parner, E. T. (2016). Association of Psychiatric and Neurologic Comorbidity With Mortality Among Persons With Autism Spectrum Disorder in a Danish Population. JAMA Pediatr 170, 243-50.

Schreibman, L., Dawson, G., Stahmer, A. C., Landa, R., Rogers, S. J., McGee, G. G., Kasari, C., Ingersoll, B., Kaiser, A. P., Bruinsma, Y., McNerney, E., Wetherby, A. \& Halladay, A. (2015). Naturalistic Developmental Behavioral Interventions: Empirically Validated Treatments for Autism Spectrum Disorder. J Autism Dev Disord 45, 2411-28.

Segers, M. \& Rawana, J. (2014). What do we know about suicidality in autism spectrum disorders? A systematic review. Autism Res 7, 507-21.

Shen, Y., Dies, K. A., Holm, I. A., Bridgemohan, C., Sobeih, M. M., Caronna, E. B., Miller, K. J., Frazier, J. A., Silverstein, I., Picker, J., Weissman, L., Raffalli, P., Jeste, S., Demmer, L. A., Peters, H. K., Brewster, S. J., Kowalczyk, S. J., Rosen-Sheidley, B., McGowan, C., Duda, A. W., 3rd, Lincoln, S. A., Lowe, K. R., Schonwald, A., Robbins, M., Hisama, F., Wolff, R., Becker, R., Nasir, R., Urion, D. K., Milunsky, J. M., Rappaport, L., Gusella, J. F., Walsh, C. A., Wu, B. L. \& Miller, D. T. (2010). Clinical genetic testing for patients with autism spectrum disorders. Pediatrics 125, e727-35.

Shire, S. Y. \& Kasari, C. (2014). Train the trainer effectiveness trials of behavioral intervention for individuals with autism: a systematic review. Am J Intellect Dev Disabil $119,436-51$.

Shivers, C. M. \& Plavnick, J. B. (2015). Sibling involvement in interventions for individuals with autism spectrum disorders: a systematic review. J Autism Dev Disord 45, 685-96.

Silberman, S. (2015). Neurotribes: The legacy of autism and the future of neurodiversity. Penguin.

Simonoff, E., Jones, C. R., Baird, G., Pickles, A., Happe, F. \& Charman, T. (2013). The persistence and stability of psychiatric problems in adolescents with autism spectrum disorders. J Child Psychol Psychiatry 54, 186-194.

Singer, A. \& Ravi, R. (2015). Complementary and alternative treatments for autism part 2: identifying and avoiding non-evidence-based treatments. AMA J Ethics 17, 375-80. 
Sinha, Y., Silove, N., Hayen, A. \& Williams, K. (2011). Auditory integration training and other sound therapies for autism spectrum disorders (ASD). Cochrane Database Syst Rev, CD003681.

Skuse, D. H., Mandy, W., Steer, C., Miller, L. L., Goodman, R., Lawrence, K., Emond, A. \& Golding, J. (2009). Social communication competence and functional adaptation in a general population of children: preliminary evidence for sex-by-verbal IQ differential risk. J Am Acad Child Adolesc Psychiatry 48, 128-37.

Soke, G. N., Maenner, M. J., Christensen, D., Kurzius-Spencer, M. \& Schieve, L. A. (2018). Prevalence of Co-occurring Medical and Behavioral Conditions/Symptoms Among 4- and 8-Year-Old Children with Autism Spectrum Disorder in Selected Areas of the United States in 2010. J Autism Dev Disord 48, 2663-2676.

Solomon, A. (2012). Far from the tree: Parents, children and the search for identity. Simon and Schuster.

Spain, D. \& Blainey, S. H. (2015). Group social skills interventions for adults with high-functioning autism spectrum disorders: A systematic review. Autism 19, 874-86. Spain, D., Sin, J., Paliokosta, E., Furuta, M., Prunty, J. E., Chalder, T., Murphy, D. G. \& Happe, F. G. (2017). Family therapy for autism spectrum disorders. Cochrane Database Syst Rev 5, CD011894.

Ssucharewa, G. E. \& Wolff, S. (1996). The first account of the syndrome Asperger described? Translation of a paper entitled "Die schizoiden Psychopathien im Kindesalter" by Dr. G.E. Ssucharewa; scientific assistant, which appeared in 1926 in the Monatsschrift fur Psychiatrie und Neurologie 60:235-261. Eur Child Adolesc Psychiatry 5, 119-32.

Staniland, J. J. \& Byrne, M. K. (2013). The effects of a multi-component higher-functioning autism anti-stigma program on adolescent boys. J Autism Dev Disord 43, 2816-29.

Stefanik, L., Erdman, L., Ameis, S. H., Foussias, G., Mulsant, B. H., Behdinan, T., Goldenberg, A., O'Donnell, L. J. \& Voineskos, A. N. (2018). Brain-Behavior Participant Similarity Networks Among Youth and Emerging Adults with Schizophrenia Spectrum, Autism Spectrum, or Bipolar Disorder and Matched Controls. Neuropsychopharmacology 43, 1180-1188.

Sturman, N., Deckx, L. \& van Driel, M. L. (2017). Methylphenidate for children and adolescents with autism spectrum disorder. Cochrane Database Syst Rev 11, CD011144. 
Sutton, B. M., Webster, A. A. \& Westerveld, M. F. (2018). A systematic review of school-based interventions targeting social communication behaviors for students with autism. Autism, 1362361317753564.

Swedish Council on Health Technology Assessment (2013). Autism Spectrum Disorders: Diagnosis and Interventions, Organization of Care and Patient Involvement. Stockholm. Szatmari, P. (2018). Risk and resilience in autism spectrum disorder: a missed translational opportunity? Dev Med Child Neurol 60, 225-229.

Tager-Flusberg, H. \& Kasari, C. (2013). Minimally verbal school-aged children with autism spectrum disorder: the neglected end of the spectrum. Autism Res 6, 468-78. Tammimies, K., Marshall, C. R., Walker, S., Kaur, G., Thiruvahindrapuram, B., Lionel, A. C., Yuen, R. K., Uddin, M., Roberts, W., Weksberg, R., Woodbury-Smith, M., Zwaigenbaum, L., Anagnostou, E., Wang, Z., Wei, J., Howe, J. L., Gazzellone, M. J., Lau, L., Sung, W. W., Whitten, K., Vardy, C., Crosbie, V., Tsang, B., D'Abate, L., Tong, W. W., Luscombe, S., Doyle, T., Carter, M. T., Szatmari, P., Stuckless, S., Merico, D., Stavropoulos, D. J., Scherer, S. W. \& Fernandez, B. A. (2015). Molecular Diagnostic Yield of Chromosomal Microarray Analysis and Whole-Exome Sequencing in Children With Autism Spectrum Disorder. JAMA 314, 895-903.

Tan, B. W., Pooley, J. A. \& Speelman, C. P. (2016). A Meta-Analytic Review of the Efficacy of Physical Exercise Interventions on Cognition in Individuals with Autism Spectrum Disorder and ADHD. J Autism Dev Disord 46, 3126-43.

Tang, L. \& Bie, B. (2016). The stigma of autism in china: an analysis of newspaper portrayals of autism between 2003 and 2012. Health Commun 31, 445-52.

Tick, B., Bolton, P., Happe, F., Rutter, M. \& Rijsdijk, F. (2016). Heritability of autism spectrum disorders: a meta-analysis of twin studies. J Child Psychol Psychiatry 57, 585-95.

Tromans, S. \& Adams, C. (2018). Brief Report: Autism Spectrum Disorder: A Comprehensive Survey of Randomized Controlled Trials. J Autism Dev Disord.

Tuchman, R., Hirtz, D. \& Mamounas, L. A. (2013). NINDS epilepsy and autism spectrum disorders workshop report. Neurology 81, 1630-6.

Turner, D., Briken, P. \& Schottle, D. (2017). Autism-spectrum disorders in adolescence and adulthood: focus on sexuality. Curr Opin Psychiatry 30, 409-416.

Uljarevic, M., Baranek, G., Vivanti, G., Hedley, D., Hudry, K. \& Lane, A. (2017). 
Heterogeneity of sensory features in autism spectrum disorder: Challenges and perspectives for future research. Autism Res 10, 703-710.

Van Drenth, A. (2018). Rethinking the origins of autism: Ida Frye and the unraveling of children's inner world in the Netherlands in the late 1930s. J Hist Behav Sci 54, 25-42.

van Schalkwyk, G. I. \& Volkmar, F. R. (2017). Autism Spectrum Disorders: Challenges and Opportunities for Transition to Adulthood. Child Adolesc Psychiatr Clin N Am 26, 329-339.

Varcin, K. J. \& Jeste, S. S. (2017). The emergence of autism spectrum disorder: insights gained from studies of brain and behaviour in high-risk infants. Curr Opin Psychiatry 30, 85-91.

Vasa, R. A., Mazurek, M. O., Mahajan, R., Bennett, A. E., Bernal, M. P., Nozzolillo, A. A., Arnold, L. E. \& Coury, D. L. (2016). Assessment and Treatment of Anxiety in Youth With Autism Spectrum Disorders. Pediatrics 137 Suppl 2, S115-23.

Veenstra-VanderWeele, J., Cook, E. H., King, B. H., Zarevics, P., Cherubini, M., Walton-Bowen, K., Bear, M. F., Wang, P. P. \& Carpenter, R. L. (2017). Arbaclofen in Children and Adolescents with Autism Spectrum Disorder: A Randomized, Controlled, Phase 2 Trial. Neuropsychopharmacology 42, 1390-1398.

Virues-Ortega, J. (2010). Applied behavior analytic intervention for autism in early childhood: meta-analysis, meta-regression and dose-response meta-analysis of multiple outcomes. Clin Psychol Rev 30, 387-99.

Virues-Ortega, J., Julio, F. M. \& Pastor-Barriuso, R. (2013). The TEACCH program for children and adults with autism: a meta-analysis of intervention studies. Clin Psychol Rev 33, 940-53.

Vivanti, G., Kasari, C., Green, J., Mandell, D., Maye, M. \& Hudry, K. (2018). Implementing and evaluating early intervention for children with autism: Where are the gaps and what should we do? Autism Res 11, 16-23.

Volkmar, F., Siegel, M., Woodbury-Smith, M., King, B., McCracken, J., State, M., American Academy of, C. \& Adolescent Psychiatry Committee on Quality, I. (2014). Practice parameter for the assessment and treatment of children and adolescents with autism spectrum disorder. J Am Acad Child Adolesc Psychiatry 53, 237-57.

Vorstman, J. A. S., Parr, J. R., Moreno-De-Luca, D., Anney, R. J. L., Nurnberger, J. I., Jr. \& Hallmayer, J. F. (2017). Autism genetics: opportunities and challenges for clinical 
translation. Nat Rev Genet 18, 362-376.

Wang, S. Y., Parrila, R. \& Cui, Y. (2013). Meta-analysis of social skills interventions of single-case research for individuals with autism spectrum disorders: results from three-level HLM. J Autism Dev Disord 43, 1701-16.

Watson, L. R., Crais, E. R., Baranek, G. T., Turner-Brown, L., Sideris, J., Wakeford, L., Kinard, J., Reznick, J. S., Martin, K. L. \& Nowell, S. W. (2017). Parent-Mediated Intervention for One-Year-Olds Screened as At-Risk for Autism Spectrum Disorder: A Randomized Controlled Trial. J Autism Dev Disord 47, 3520-3540.

Weiner, D. J., Wigdor, E. M., Ripke, S., Walters, R. K., Kosmicki, J. A., Grove, J., Samocha, K. E., Goldstein, J. I., Okbay, A., Bybjerg-Grauholm, J., Werge, T., Hougaard, D. M., Taylor, J., i, P.-B. A. G., Psychiatric Genomics Consortium Autism, G., Skuse, D., Devlin, B., Anney, R., Sanders, S. J., Bishop, S., Mortensen, P. B., Borglum, A. D., Smith, G. D., Daly, M. J. \& Robinson, E. B. (2017). Polygenic transmission disequilibrium confirms that common and rare variation act additively to create risk for autism spectrum disorders. Nat Genet 49, 978-985.

Weiss, J. A., Isaacs, B., Diepstra, H., Wilton, A. S., Brown, H. K., McGarry, C. \& Lunsky, Y. (2018). Health Concerns and Health Service Utilization in a Population Cohort of Young Adults with Autism Spectrum Disorder. J Autism Dev Disord 48, 36-44.

Weitlauf, A. S., McPheeters, M. L., Peters, B., Sathe, N., Travis, R., Aiello, R., Williamson, E., Veenstra-VanderWeele, J., Krishnaswami, S., Jerome, R. \& Warren, Z. (2014). Therapies for Children With Autism Spectrum Disorder: Behavioral Interventions Update. (ed. U. S. D. o. H. a. H. S. Agency for Healthcare Research and Quality): Rockville (MD). Weitlauf, A. S., Sathe, N., McPheeters, M. L. \& Warren, Z. E. (2017). Interventions Targeting Sensory Challenges in Autism Spectrum Disorder: A Systematic Review. Pediatrics 139.

Weston, L., Hodgekins, J. \& Langdon, P. E. (2016). Effectiveness of cognitive behavioural therapy with people who have autistic spectrum disorders: A systematic review and meta-analysis. Clin Psychol Rev 49, 41-54.

Whalon, K. J., Conroy, M. A., Martinez, J. R. \& Werch, B. L. (2015). School-based peer-related social competence interventions for children with autism spectrum disorder: a meta-analysis and descriptive review of single case research design studies. J Autism Dev Disord 45, 1513-31. 
Wheelwright, S., Auyeung, B., Allison, C. \& Baron-Cohen, S. (2010). Defining the broader, medium and narrow autism phenotype among parents using the Autism Spectrum Quotient (AQ). Mol Autism 1, 10.

Whitehouse, A. J. (2013). Complementary and alternative medicine for autism spectrum disorders: rationale, safety and efficacy. J Paediatr Child Health 49, E438-42:quiz E442.

Williams, K., Brignell, A., Randall, M., Silove, N. \& Hazell, P. (2013). Selective serotonin reuptake inhibitors (SSRIs) for autism spectrum disorders (ASD). Cochrane Database Syst Rev, CD004677.

Williams, K., Wray, J. A. \& Wheeler, D. M. (2012). Intravenous secretin for autism spectrum disorders (ASD). Cochrane Database Syst Rev, CD003495.

Williams, K. W., Wray, J. J. \& Wheeler, D. M. (2005). Intravenous secretin for autism spectrum disorder. Cochrane Database Syst Rev, CD003495.

Wing, L. (1975). The autistic spectrum: A guide for parents and professionals. Constable \& Robinson Ltd.: London, UK.

Wink, L. K., Minshawi, N. F., Shaffer, R. C., Plawecki, M. H., Posey, D. J., Horn, P. S., Adams, R., Pedapati, E. V., Schaefer, T. L., McDougle, C. J., Swiezy, N. B. \& Erickson, C. A. (2017). d-Cycloserine enhances durability of social skills training in autism spectrum disorder. Mol Autism 8, 2.

Wolstencroft, J., Robinson, L., Srinivasan, R., Kerry, E., Mandy, W. \& Skuse, D. (2018). A Systematic Review of Group Social Skills Interventions, and Meta-analysis of Outcomes, for Children with High Functioning ASD. J Autism Dev Disord 48, 2293-2307.

Wong, C., Odom, S. L., Hume, K. A., Cox, A. W., Fettig, A., Kucharczyk, S., Brock, M. E., Plavnick, J. B., Fleury, V. P. \& Schultz, T. R. (2015). Evidence-Based Practices for Children, Youth, and Young Adults with Autism Spectrum Disorder: A Comprehensive Review. J Autism Dev Disord 45, 1951-66.

Xiong, T., Chen, H., Luo, R. \& Mu, D. (2016). Hyperbaric oxygen therapy for people with autism spectrum disorder (ASD). Cochrane Database Syst Rev 10, CD010922.

Yamasue, H., Okada, T., Munesue, T., Kuroda, M., Fujioka, T., Uno, Y., Matsumoto, K., Kuwabara, H., Mori, D., Okamoto, Y., Yoshimura, Y., Kawakubo, Y., Arioka, Y., Kojima, M., Yuhi, T., Owada, K., Yassin, W., Kushima, I., Benner, S., Ogawa, N., Eriguchi, Y., Kawano, N., Uemura, Y., Yamamoto, M., Kano, Y., Kasai, K., Higashida, H., Ozaki, N. \& Kosaka, H. (2018). Effect of intranasal oxytocin on the core social symptoms of autism 
spectrum disorder: a randomized clinical trial. Mol Psychiatry.

Yang, D., Pelphrey, K. A., Sukhodolsky, D. G., Crowley, M. J., Dayan, E., Dvornek, N. C., Venkataraman, A., Duncan, J., Staib, L. \& Ventola, P. (2016). Brain responses to biological motion predict treatment outcome in young children with autism. Transl Psychiatry 6, e948.

Yatawara, C. J., Einfeld, S. L., Hickie, I. B., Davenport, T. A. \& Guastella, A. J. (2016). The effect of oxytocin nasal spray on social interaction deficits observed in young children with autism: a randomized clinical crossover trial. Mol Psychiatry 21, 1225-31.

Zahid, S. \& Upthegrove, R. (2017). Suicidality in Autistic Spectrum Disorders. Crisis 38, 237-246.

Zaidman-Zait, A., Mirenda, P., Duku, E., Szatmari, P., Georgiades, S., Volden, J., Zwaigenbaum, L., Vaillancourt, T., Bryson, S., Smith, I., Fombonne, E., Roberts, W., Waddell, C., Thompson, A. \& Pathways in, A. S. D. S. T. (2014). Examination of bidirectional relationships between parent stress and two types of problem behavior in children with autism spectrum disorder. J Autism Dev Disord 44, 1908-17.

Zwaigenbaum, L., Bauman, M. L., Choueiri, R., Kasari, C., Carter, A., Granpeesheh, D., Mailloux, Z., Smith Roley, S., Wagner, S., Fein, D., Pierce, K., Buie, T., Davis, P. A., Newschaffer, C., Robins, D., Wetherby, A., Stone, W. L., Yirmiya, N., Estes, A., Hansen, R. L., McPartland, J. C. \& Natowicz, M. R. (2015). Early Intervention for Children With Autism Spectrum Disorder Under 3 Years of Age: Recommendations for Practice and Research. Pediatrics 136 Suppl 1, S60-81. 